\title{
INTER-LINGUAL INTERFERENCE IN A BILINGUAL VERSION OF THE STROOP COLOR-WORD TASK
}

by

\author{
Malcolm S. Preston
}

\begin{abstract}
A thesis submitted to the Faculty of Graduate Studies and Research in partial fulfilment of the requirements for the degree of Doctor of Philosophy.
\end{abstract}

\footnotetext{
Department of Psychology

McGill University

Montreal
}

September, 1965 


\section{ACKNOWLEDGEMENTS}

The research reported in this thesis was supported by grants from the Defense Research Board of Canada (No. 272-83) and the Carnegie Corporation of America (No. 270-92) to Dr. Wallace E. Lambert. The author is indebted to Howard Blanchette, Gisele Stahlberg, David Nyberg, Rosanne Baetz and Ken Williamson for their assistance in gathering the data and to Elizabeth Shannon, Dick Tucker and Grace Yeni-Komshian for their advice and criticism. 


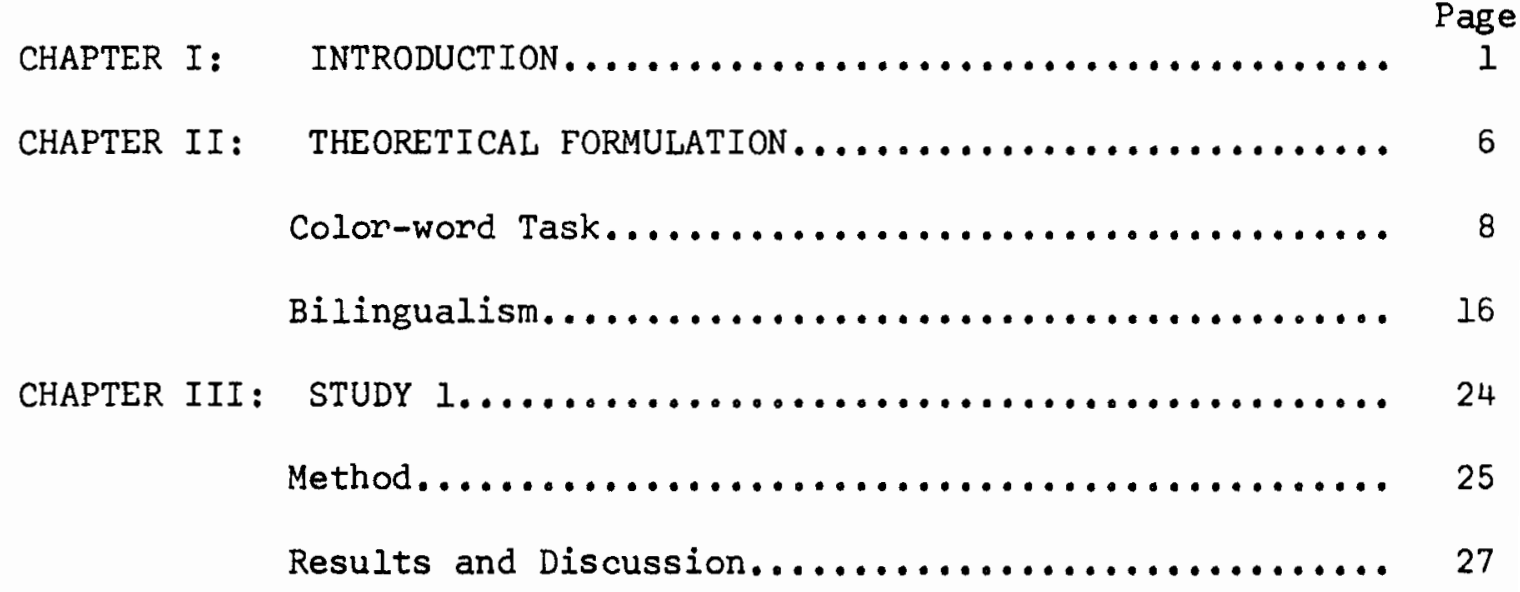

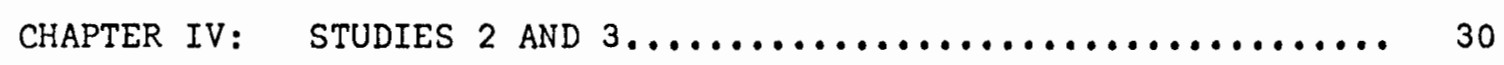

Method (Study 2)............................ 31

Results (study 2 )................................ 34

Discussion (study 2$) \ldots \ldots \ldots \ldots \ldots \ldots \ldots \ldots \ldots \ldots \ldots \ldots \ldots$

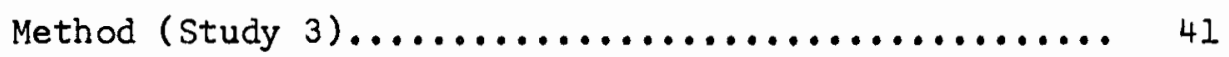

Results (study 3$) \ldots \ldots \ldots \ldots \ldots \ldots \ldots \ldots \ldots \ldots \ldots \ldots \ldots$

Discussion (study 3 ).................... 45

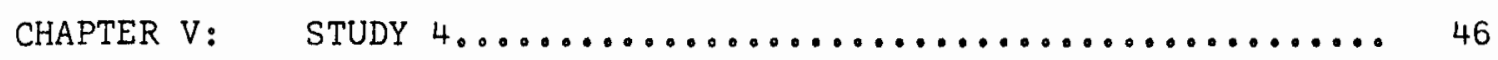

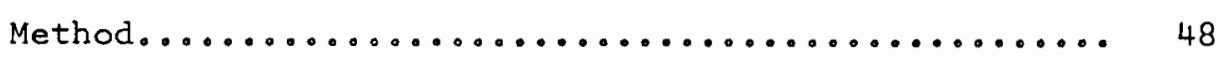

Results and Discussion........................ 50

CHAPTER VI: OVERVIEW AND DISCUSSION................... 54

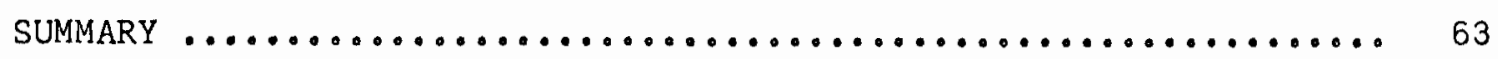

REFERENCES.................................. 66

APPENDICES. $\ldots \ldots \ldots \ldots \ldots \ldots \ldots \ldots \ldots \ldots \ldots \ldots \ldots \ldots \ldots \ldots \ldots \ldots$ 


\section{FIGURES}

Page

FIGURE 1: Proposed word reading subsystem............... 8 a

FIGURE 2: Proposed color naming subsystem............... 12a

FIGURE 3: Processes involved for the color-word task, Card C.. 15a 
CHAPTER I

INTRODUCTION

One noteworthy characteristic of the fully bilingual person is his ability to function in one of his languages with a minimum of disruptive interference from the other. However, occasional interference suggests that the two language systems may come in contact or overlap in some fashion. Questions concerning the degree to which the two language systems overlap and the points at which the overlap occurs have been raised by both linguists and psychologists.

One linguist, (Weinreich, 1953) makes a distinction between two types of bilingualism variously referred to as "pure vs. mixed," "organic vs. inorganic" or "subordinate vs. coordinative." The distinction is based on differences in the language behavion of bilinguals such as the facility to translate from one language to another. Similar sorts of distinctions can be found in the psychological literature. One theory (Ervin \& Osgood, 1954) proposes that for some bilinguals equivalent signs (translations) in the two languages may activate the same meaning unit, 
while for other bilinguals equivalent signs in the two languages may activate different meaning units. These two types of bilingualism are referred to as "compound" and "coordinate" respectively. Presumably the manner in which the two languages are acquired determines, in part, whether a bilingual uses his languages in a compound or coordinate fashion. According to this hypothesis, overlap occurs at the meaning unit level. Several pilot studies have found support for the compoundcoordinate hypothesis (Lambert, Havelka, $\varepsilon$ Crosby, 1958; Lambert $\varepsilon$ Fillenbaum, 1959; Lambert, 1962; Jakobovits $\&$ Lambert, 1961). Another study (Olton, 1960) by the same research group did not find support, however.

Closely related to the compound-coordinate hypothesis is one recently proposed by Kolers (1963). Kolers suggests two possibilities: (1) that events are coded once in common and that the two language systems tap this common store, or (2) that events are coded separately in the particular language system in use during the occurrence of the event. Kolers presented data showing that in a word association test one third of the responses in one language to stimulus words in that language were translations of responses to translated stimulus words in the other language. In addition, he found that language acquisition history was not a significant variable, that is, that $\underline{S}$ with different language acquisition histories may have similar scores while those with similar histories may have different scores. Kolers feels this evidence supports the hypothesis of separate coding.

Recent theorizing on the nature of language systems favors a multi-process view. From this perspective, a language system consists of 
several different processes, each concerned with a particular operation. For instance, Chomsky (1957) has been concerned with processes dealing with the problem of syntactic organization. Other researchers, particularly those at the Haskins Laboratories (Liberman, Cooper, Harris, E MacNeilage, 1962) have been concerned with the more peripheral aspects of the language system:the relations between the neural commands, articulatory gestures and acoustic output. Thus from this point of view, the execution of a linguistic task would involve a particular sub-set of processes (subsystem) organized in such a way as to produce the desired result. For instance, the subsystem for naming objects would involve only some of the processes of the language system. Most likely, this subsystem would not include processes concerned with syntactic organization.

Extending this view to bilingual language systems, one may then ask the general question: how distinct are the two language systems? For instance, does the operation of processes in one language system make the other language system inoperative? Penfield in Penfield \& Roberts (1959) suggests that there is a switching mechanism which effectively shuts off one language system while the other is in operation. One way of exploring this question is to determine whether one can produce interference in a subsystem functioning in one language by structuring the stimulus situation so as to encourage the operation of another potentially interfering subsystem in the other language. Penfield's hypothesis would predict relatively little interference in this situation.

The present series of experiments examines inter-language interference from this competing subsystem viewpoint. A situation particularly likely to put subsystems (color naming vs. word reading) in competition 
is the color-word task first introduced by Stroop (1935a). In this task a card containing ten rows of ten words is presented to $\underline{S}$. Each of the words is printed in one of four different colors. The words themselves are the names of colors and no word ever appears in the color it names. For instance, the word RED might be printed in blue, green or brown ink, but never in red ink. S's task is to name the color of the inks of the words as fast and as accurately as possible. To be efficient, he must ignore the words and simply concentrate on the colors of the inks. Usually at the beginning of the experiment, $\underline{S}$ is asked to name the colors on another card containing patches or blocks of color; the order of ink-colors on this card is the same as on the color word card. In some experiments, $\underline{S}$ is also asked to respond to a third card. On the third card, words (names of colors) are printed in black ink and the task is simply to read the words aloud.

If $\underline{S}$ is asked to perform all three tasks, the time scores invariably fall in the following pattern (Rand, Wapner, Werner, \& McFarland, 1963):

1. Card A: reading the names of color words in black ink-lowest time score.

2. Card B: naming the colors of patches or blocks-- intermediate time score.

3. Card C: naming the ink colors of words--highest time score.

The fact that Card $C$ always takes the most time to complete suggests that processes involved in word reading interfere in some fashion with the processes involved in color naming. In the present series of 
experiments, a modified version of the color-word task was employed so that both intra-language and inter-language interference could be examined. The basic design of these experiments employed Cards $B$ and $C$. The makeup of Card B varied from experiment to experiment. In some cases blocks of colors were used, in other cases wavy lines, astericks or meaningless letter series were used. There were two forms of Card C which were identical except for the fact that all the wcrds on one card were in one language while all the words on the other card were in another language. Words in corresponding positions on these two cards were translations. Bilinguals served as SS. During the course of the experiment they named the colors of words or patches in both languages on all three cards, (Card B and the two forms of Card C) making a total of six time scores for each $\underline{S}$.

The aim of the present experiments was to determine to what extent and under what conditions inter-lingual interterence could be produced in the bilingual version of the color-word task described atove. Chapter II first reviews several theories of the nature sf the interference found in the colcrmword task and then presents a new theoretical formulation, drawing on an information processing modes, applicable to the bingual situation. The protiem of bilingual dominance is deall with and a set of predictions is inade for both balanced and dominant bilinguals. The following chapters present the results of several experi... merts along with an incerpretation of the results. 
CHAPTER II

THEORETICAL FORMULATION

Although the differences noted in time to perform on Cards A, $B$ and $C$ are highly reliable, there has been relatively little theorizing to account for these findings. Early researchers (Stroop, 1935a, 1935b, 1938) attributed the differences in time to complete Cands $A$ and $B$ to differential practice in naming (reading) the printed word and naming colors of objects. They argued that while only one primary response (reading) is made to words, many responses beside naming can be made to a patch of color. Interference between these two response tendencies of different strength and complexity accounts for the longest time score noted on Card C.

More recently Rand et al. (1963) have proposed another somewhat related theory. In performing on all three cards they feel that two interrelated processes are involved: (1) an identification process and (2) a serial organization process. The identification process selects the appropriate stimulus feature for the required response and the serial 
organization process arranges the responses smoothly in the proper sequence. Going from Card A through Card C, the complexity of selectivity (identification process) increases with the net result that more time is required.

Basically, the model to be proposed in this chapter is a simple one. Two subsystems, one for color naming and one for word reading are postulated. Each subsystem is composed of several processes including a motor process for the production of spoken words. It is assumed that (1) the efficiency of a process increases with practice and (2) the word reading subsystem as a whole is the more highly practiced of the two, and thus functions in an automatic fashion when presented with an appropriate stimulus. When the color bearing stimulus in the color-word task is a word, both subsystems will be activated. A selective process is postulated which attempts to "gate out" the highly automatic word reading subsystem thus permitting the color naming subsystem to function unimpeded. The more dissimilar the two kinds of information being processed by the two subsystems, the more efficient the selective process will be in "gating out" the interfering word reading subsystem。

In the discussion to follow, the processes postulated are examined in greater detail in order to present the general flavor of the kind of model proposed here. No attempt is made to link any of the processes to the underlying neurological hardware. Some of the important problems each process must solve are discussed and some similarities between these processes and those recently proposed by other researchers are indicated. The predictions which follow in the latter part of this chapter, however, are based solely upon the functions. 
assigned to the processes and the factors assumed to affect their efficiencies of operation. Thus confirmed predictions should not be taken as conclusive evidence supporting the more detailed account to be presented shortly. They suggest only that the kind of model proposed may be feasible.

Color-word task

On Card $A$ the task is to read aloud the names of colors as they are written on the card, while on Card B the task is to name the colors of patches. As long ago as 1915, Brown suggested that word reading and color naming may involve different mechanisms. According to Brown, naming a color involves at least two processes, perception and search for response, while reading a word may involve only one thoroughly learned perceptual response. The increased time found on Card B would be accounted for by the extra process involved in color naming. The view adopted here enlarges upon Brown's speculations.

Cand $A$. While Brown suggested that reading a single word aloud involves one process, the present view suggests that at least two processes are involved in this task: a perceptual or input process for words and a motor process. The function of the input process for words is to activate a unit (word-unit) corresponding uniquely to the word being read. Once a word-unit is activated, it can act as the input to a motor process which has as its end result the production of the word by the articulatory apparatus. The word-unit proposed in this account does not correspond to any mechanism underlying the meaning of the word. The word-unit can act, however, as the input to a meaning search process which would activate as its end result one of several meaning-units appropriate to the context. Figure 1 presents the proposed word reading subsystem。 


\section{Printed word to be}

read aloud

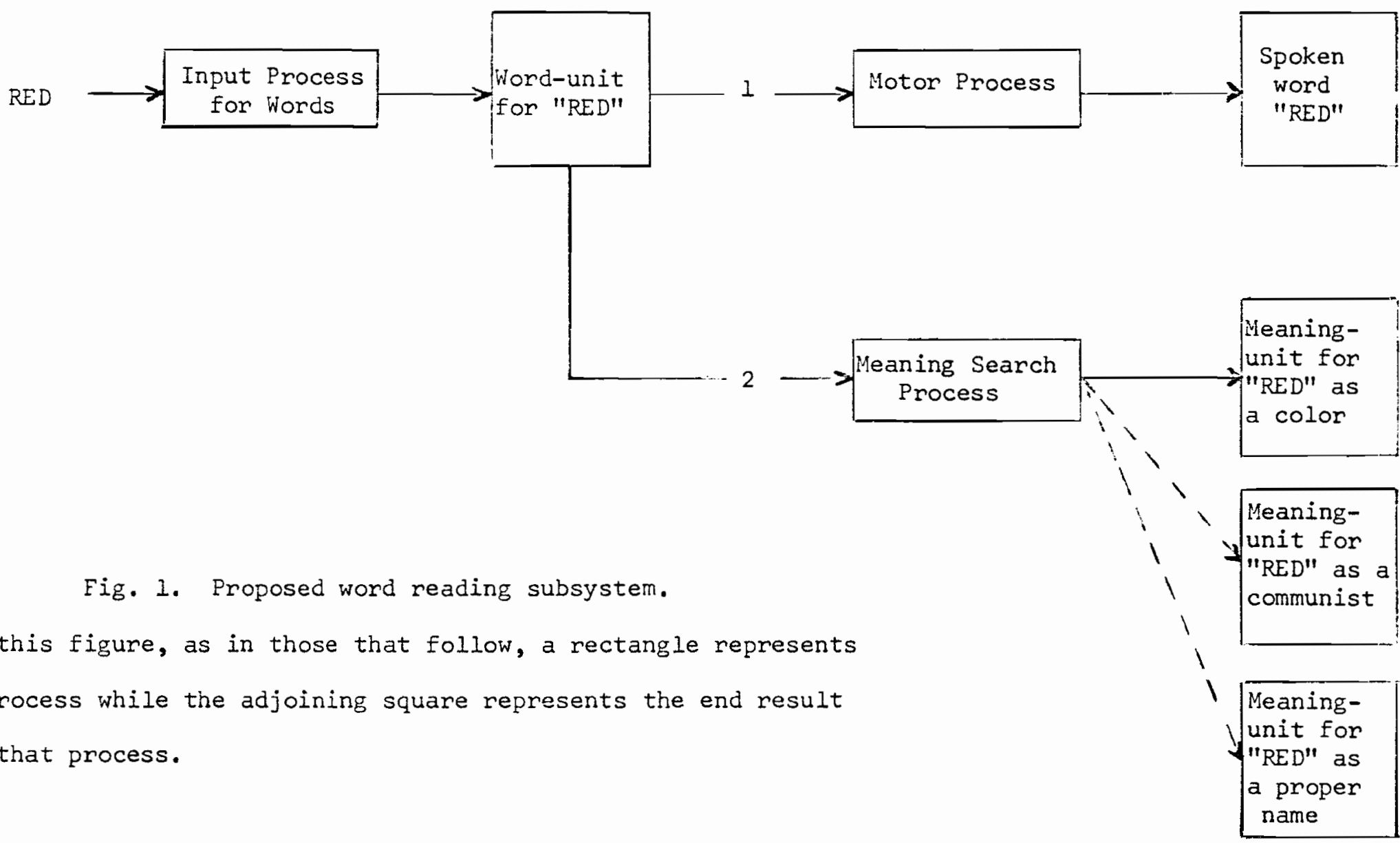


If both branches from the word-unit are functioning, the word will not only be produced verbally but understanding will also occur.

The model outlined above does not differ markedly from other recent theoretical accounts of the way in which language systems operate. For instance, a model proposed by 0sgood (1963) suggests that each word presented in the auditory or visual mode evokes a unique, corresponding activity in a "Word Form Pool." The activity in the "Word Form Pool" can then act as the input to a "Semantic Key Sort" which is a device that activates the appropriate meaning-response taking into account the context in which the word is used. An activity in the "Word Form Pool" and the "Semantic Key Sort", correspond in the present account to an activated word-unit and the meaning search process respectively.

The present account also bears resemblance to notions advanced by researchers at The Haskins Laboratories (Liberman, Cooper, Harris, MacNeilage, $\varepsilon$ Studdert-Kennedy, 1964). They suggest that some of the same mechanisms involved in the production of speech are also involved in the perception of speech. They assume that a unique set of signals exists in a speaker's central nervous system corresponding in a one to one fashion with the phonemes used in his language. They hypothesize that these signals function in both the reception and production of speech sounds. A particular sub-set of these phonemic signals, activated perhaps in a temporal pattern, would constitute an activated word-unit in the present account, and as Figure 1 indicates, the word-unit functions in both production and perception (branches $I$ and 2 respectively)。

A third theoretical formulation similar to the present one has been offered by Morton \& Broadbent (1964)。 This "model has as its central 
feature a 'dictionary' of 'units' or 'logogens' which correspond to words. When the activation in a logogen exceeds a critical level it fires, and the corresponding word is available as a response, that is, a representation of the appropriate motor sequence is stored in the Immediate Memory." Logogens may be activated by higher order processes (ideogens or thought units) or by sensory input, thus permitting logogens to function in both the production and the perception of speech. The logogen is equivalent to the word-unit in the present account. Returning now to the input process for words and the way in which it functions, one very important task it must solve is the many-to-one mapping problem (Uhr, 1963). A word may have many different stimulus configurations; for instance, the word may appear in different type fonts or different styles of handwriting. These different stimulus configurations must eventually activate the same unit. Programs written by Selfridge $\varepsilon$ Neisser (1960), and Uhr \& Vossler (1961) are attempts to solve the many-to-one mapping problem with machine recognizers. A model of letter recognition in humans which also deals with the many- toone mapping problem is presented by Neisser (1964)。 The present formulation assumes that the efficiency of the input process for words for prow cessing a given word increases with the number of times it has experience with that word. Stated in other terms, high frequency words should be processed more quickly and with less effort than low frequency words. Research showing a relationship between frequency of word occurrence and visual duration thresholds is consistent with this assumption (Rosenzweig \& Postman, 1958; Postman \& Conger, 1954)。

The motor process shown in Figure 1 takes as its input a word- 
unit and produces as its output the spoken word. Some of the problems to be solved by motor processes are discussed at length in Lenneberg (1964). For instance, under the headings of "Speech Production" and "Problems Arising from Rate and Ordering," Lenneberg shows that the order of central motor command events must be different from the order of peripheral muscular events because of different conduction rates of nervous tissue leading to the various muscles of the articulatory apparatus. This suggests that motor processes, in part, must contain some sort of integrator capable of dealing with the necessary transformation between central and peripheral motor events. For present purposes, the only assumption made about the motor process is again one of frequency: the more often a given word is produced verbally, the more efficient the motor process becomes for the production of that word.

The meaning search process and the meaning-units shown in Figure 1 are less crucial for the predictions made for the present experiments. Attention has already been drawn to the similarity between Osgood's "Semantic Key Sort" and the meaning search process and for the time being no more will be said about these processes except that they handle the problem of context in the activation of the appropriate meaning-unit. The meaning-unit itself may be thought of as roughly equivalent to the representational mediation process proposed by Osgood (1953).

Card B. Brown (1915) suggested that color naming involves two mechanisms: a perceptual process and a search for response process. The present formulation adopts this view with some minor modifications. To 
be consistent with the processes postulated for Card A, Brown's search for response process is divided into two separate processes: a word search process and a motor process. These two processes, together with the perceptual process (renamed the input process for color), constitute the color naming subsystem which is presented in Eigure 2.

The function of the input process for color is to activate a color-unit corresponding to the stimulus color. An activated color-unit can then act as the input to a word search process which would yield as its output a word-unit corresponding to the appropriate color. The word-unit would then act as the input to a motor process, thus producing the name of the color as a verbal response.

Many-to-one mapping may also be a problem for both the input process for color and the word search process. For instance, the perception of a color usually remains constant under moderate variations in brightness and the same name is often given to several different shades. The present account assumes (1) that of these two processes only the word search process is part of the language system and (2) that the efficiency of both processes is affected by frequency of usage.

Research which tends to support the distinction made between perceptual and word searching processes in color naming comes from Istomina (1963). In this study, it was found that small children performed with relatively few errors on a color matching task although they had not yet learned the names of the colors they were matching. In addition, the three process model for color naming is not inconsism 


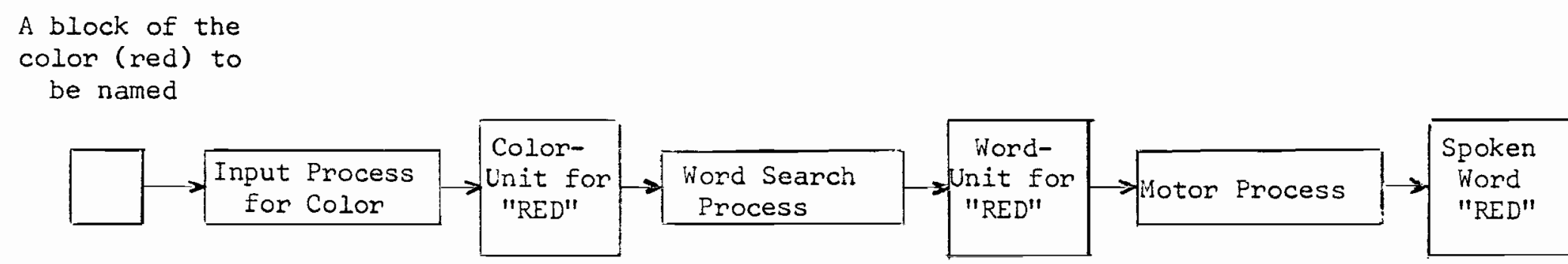

Fig. 2. Proposed color naming subsystem. 
tent with the kind of model that would be suggested by clinical data on aphasia. Penfield \& Roberts (1959) list inability to name with retained ability to speak as one of the effects produced by applying a small current at various points in the speech areas of the cortex. They describe a patient who was unable to name a picture of a comb when current was applied, but who was still able to describe accurately its use.

Card $c$. On this card the task is to name the colors (inks) that the words are printed in, the words themselves being the names of colors. Invariably, Ss take more time to complete Card $c$ than card $B$ and they often read the printed word rather than name its color, which suggests that word reading interferes in some fashion with color naming. The present formulation takes this point of view. It assumes that because reading is such a well practiced activity, the word reading subsystem underlying this activity becomes highly automatic and thus hard to inhibit. Under ideal circumstances, of course, the word reading subsystem should remain inactive while the color naming subsystem is operative. If both subsystems operate simultaneousiy, interference may result。

Stated in terms of the processes postulated for Cards A and $B$, the following explanation is suggested to account for the increased time taken to complete card $C$. For color naming or word reading performed separately, as soon as a word-unit is activated it can act immediately as the input to the motor process. On Card $c$, because of the assumed automatic character of the word reading system, two wordunits are activated, one by the input process for words corresponding 
to the printed word, and the other by the word search process corresponding to the color of the printed word. Thus on Card $C$ activation of a word-unit can not automatically trigger off the motor process. On this card, then, in addition to the processes outlined for Cards $A$ and $B$, a selective process is postulated which has as its function the inhibition of the word reading subsystem, at the same time permitting the color naming subsystem to operate. It is assumed that the efficiency of the selective process is a function of the distinctiveness of the information being processed by the two subsystems that it is attempting to affect differentially. For instance, a prediction based on this assumption will be made shortly that less time should be taken to complete a card when the words on the card are not the names of color than to complete a card when the words on the card are the names of colors. In the first case, one subsystem (word reading) is processing non-color words and the other subsystem (color naming) is processing color words, while in the second case both subsystems are processing color words. The above assumption simply suggests that it is easier for the proposed selective process to affect differentially two subsystems when they are processing different kinds of material.

It is assumed that the proposed selective process is programmed by the task instructions. These instructions caution $\underline{S}$ to ignore the printed words and pay attention only to the ink color of the words. One way such a selective process might work within the context of the present formulation would be by selectively facilitating word-units that correspond to the names of colors. The facilitation would be sub 
threshold so that no word-units would be directly activated. However, the effect would be to decrease the extra amount of facilitation necessary to activate the word-units corresponding to correct responses. A similar hypothesis is made by Morton $\&$ Broadbent (1964) to account for the effect of context in sentence recognition. They suggest that activation of certain logogens by higher order processes (context) decreases the amount of sensory input necessary to make the same logogens fire. It is also possible that the selective process may exert its effect by direct inhibition of the input process for words. Thus, the present formulation does not limit the selective process to any particular locus of influence. Figure 3 outlines the processes postulated for Card c.

As suggested earlier, the formulation offered here is by no means complete. For instance, no mention has been made of feedback mechanisms which signal the completion of a response so that the next one can be initiated (Chase, 1963). Also, no mention has been made of memory storage mechanisms which probably would play an important role in an information processing model of this type. However, the model as it stands now is sufficiently detailed to permit the following simple predictions.

1. The time scores should increase from Card A through Card C. Card B should take more time than Card A because (a) there are more processes involved for Card $B$ and (b) naming (reading) words is probably a more highly practiced response than naming the colors of objects. Card $C$ should take the most time 


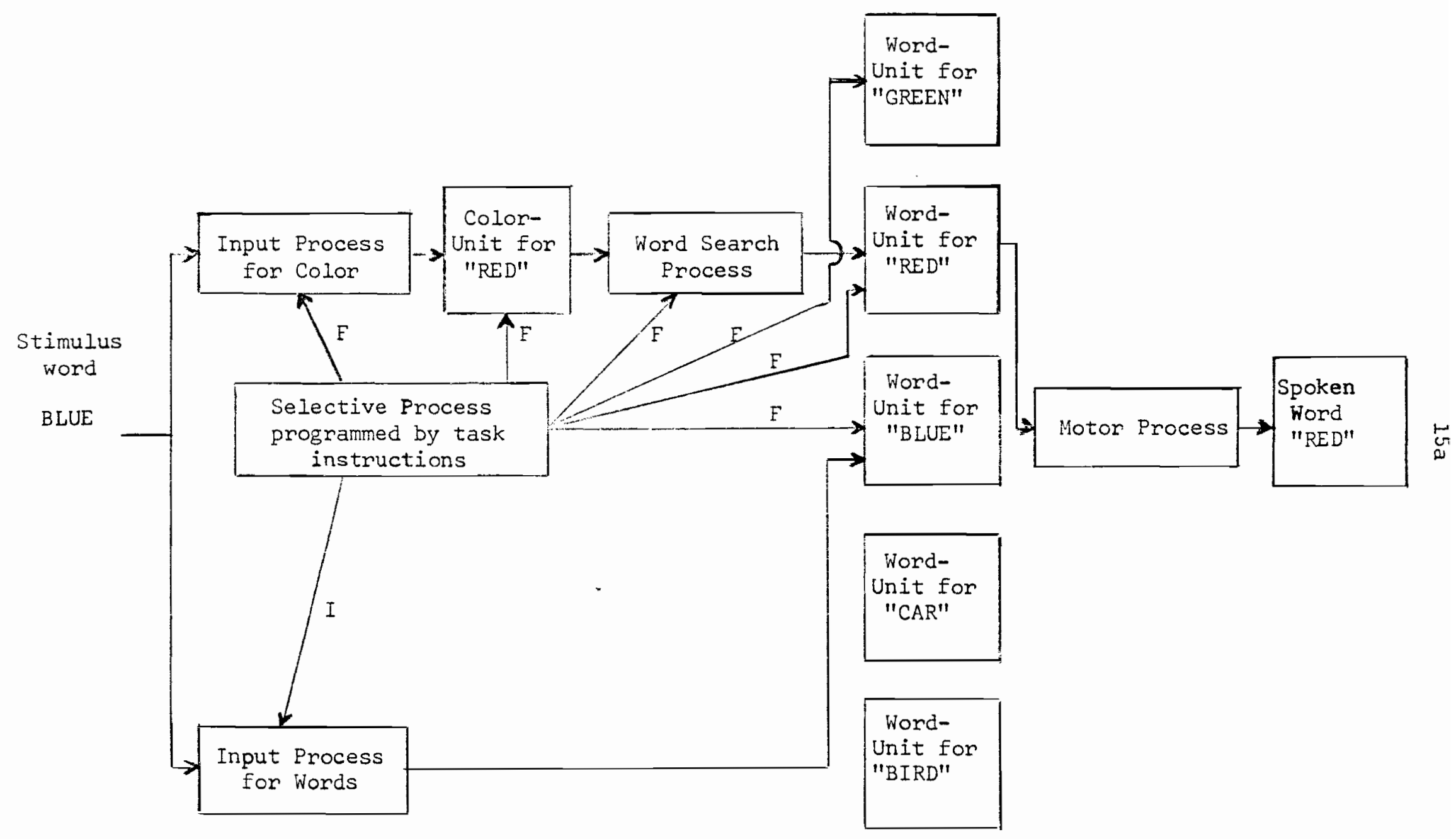

Fig. 3. Processes involved for the color-word task, Card.C. Some of the activities the selective process may facilitate or inhibit are indicated by the letters $F$ and I respectively. 
because of the operation of the selective process.

2. Other factors held constant, on Card C non-color words should cause less interference than color words (selective process)。

3. Other factors held constant, high frequency words should cause more interference than low frequency words since the input process for words (the first step in the interfering word reading subsystem) handles high frequency words more efficiently than low frequency words.

Prediction 1 fits the results of Rand et al. (1963). Predictions 2 and 3 find support in a study by Klein (1964)。Predictions 2 and 3 are replicated in the first experiment described in this paper.

\section{Bilingualism}

In one of the bilingual versions of the color-word task, two forms of Card $C$ are used. One of these cards contains color words from Language 1 and the other card contains color words from Language 2. Corresponding words on these two cards are translations. Bilingual Ss name the colors of the words on both cards at some point in the experiment in both languages, making four combinations. For instance, if the two languages are English and French, they would name (1) the English Card C in English, (2) the English Card C in French, (3) the French Card C in English, and (4) the French Card C in French. In addition, they would also name the colors of patches on a third card 
(Card B) in both languages.

Previous research indicates that the color naming subsystem will suffer interference from the word reading subsystem when both are functioning in the same language. The question now arises: will a color naming subsystem functioning in one language suffer interference from a word reading subsystem functioning in another language, and if so, will the interference be as much as that when the two subsystems are functioning in the same language? In extending the theoretical formulation to the bilingual situation, one may ask whether bilingual language systems require corresponding processes or whether the same process can function in two different modes. For instance, should one postulate two distinct input processes for words, one for each language, or is one input process for words sufficient for both languages? The same question can also be asked about the end result of a process. For example, in an earlier section it was suggested that a word-unit consisted of a temporal sequence of signals, each signal representing a phoneme. Since all language pairs probably share some phonemes, the question may be asked whether word-units in the two language systems of a bilingual make use of the same bank of phoneme signals on whether each language system possesses its own phoneme bank?

Although more detailed questions of this type are inportant, the experiments to be reported can at best give only suggestive answers 。 The view tentatively taken by the present formulation is that one input process for words, one word search process and one motor process serve for both languages; that is, it is assumed that these three processes can function as parts of subsystems in either language. According to 
this view then, a French-English bilingual is considered balanced if on the average these three processes function as efficiently in one language as they do in the other. However, for the predictions to be made shortly, it is sufficient simply to specify (1) the language in which the process is functioning and (2) the efficiency of the process. Table 1 summarizes the factors affecting scores in the bilingual color word situation for French-English bilinguals.

Since it is assumed that the input process for words, the word search process and the motor process function equally well in both languages for "balanced" bilinguals, these factors should not affect differences in time scores in Table 1. Thus "balanced" bilinguals should show no difference between cells 3 and 6 . In addition, Cells 1 and 5 should have greater time scores than Cells 3 and 6 respectively, reflecting the usual interference in color naming by the word reading subsystem. According to the present formulation, the selective process will function more efficiently in Cells 2 and 4 compared to Cells 1 and 5. It is assumed that the efficiency of the selective process is affected by the distinctiveness of the information being processed by the two subsystems; thus, the efficiency of this process shouid be greater when the two subsysters are functioning in different languages (Cells 2 and 4), and less when the two subsystems are functioning in the same language (Cells 1 and 5). If Penfield's notion of a switch mechanism is correct, there should be no difference in time scores between cells 2 and 3 , or between cells 4 and 6 . It is apparent from the above discussion that there are several different ways in which a bilingual could be dominant in one of 
Table 1

Factors Affecting Time Scores in the Bilingual Color-Word Task

\begin{tabular}{|c|c|c|c|c|c|c|}
\hline \multirow{3}{*}{$\begin{array}{l} \\
\text { English } \\
\text { Response }\end{array}$} & \multicolumn{2}{|c|}{ English Card C } & \multicolumn{2}{|c|}{ French Card C } & \multicolumn{2}{|c|}{ Card B } \\
\hline & $\operatorname{cell}$ & & $\mathrm{Cell}$ & & $\mathrm{Cell}$ & 3 \\
\hline & $\begin{array}{l}\text { 1. Input process } \\
\text { for words } \\
\text { 2. Word search } \\
\text { process } \\
\text { 3. Selective } \\
\text { process } \\
\text { 4. Motor process }\end{array}$ & $\begin{array}{l}\text { - English } \\
\text { - English } \\
\text { - English }\end{array}$ & $\begin{array}{l}\text { 1. Input process } \\
\text { for words } \\
\text { 2. Word search } \\
\text { process } \\
\text { 3. Selective } \\
\text { process } \\
\text { 4. Motor process }\end{array}$ & $\begin{array}{l}\text { - Erench } \\
\text { - English } \\
\text { - English }\end{array}$ & $\begin{array}{l}\text { 1. Input process } \\
\text { for words } \\
\text { 2. Word search } \\
\text { process } \\
\text { 3. Selective } \\
\text { process } \\
\text { 4. Motor process }\end{array}$ & $\begin{array}{l}\text { - Nil } \\
\text { - English } \\
\text { - Nil } \\
\text { - English }\end{array}$ \\
\hline $\begin{array}{r}\text { French } \\
\text { Response }\end{array}$ & $\begin{array}{l}\text { Cell } \\
\text { 1. Input process } \\
\text { for words } \\
\text { 2. Word search } \\
\text { process } \\
\text { 3. Selective } \\
\text { process } \\
\text { 4. Motor process }\end{array}$ & $\begin{array}{l}4 \\
\text { - English } \\
\text { - French } \\
\text { - French }\end{array}$ & $\begin{array}{l}\text { Cell } \\
\text { 1. Input process } \\
\text { for words } \\
\text { 2. Word search } \\
\text { process } \\
\text { 3. Selective } \\
\text { process } \\
\text { 4. Motor process }\end{array}$ & $\begin{array}{l}5 \\
\text { - French } \\
\text { - French } \\
\text { - French }\end{array}$ & $\begin{array}{l}\text { Cell } \\
\text { 1. Input process } \\
\text { for words } \\
\text { 2. Word search } \\
\text { process } \\
\text { 3. Selective } \\
\text { process } \\
\text { 4. Motor process }\end{array}$ & $\begin{array}{l}6 \\
\text { - Nil } \\
\text { - French } \\
\text { - Nil } \\
\text { - French }\end{array}$ \\
\hline
\end{tabular}


his languages. For instance, a person who does an equal amount of reading in both languages, but relatively more speaking in one language than the other, may have an input process for words that functions equally well in the two languages, but a word search process and a motor process that function more efficiently in one of the two languages. However, for many bilinguals the efficiencies of these three processes are probably highly intercorrelated.

In the case where the input process for words, the word search process and the motor process function more efficiently in one language than the other (French-English bilingual with English dominant), the following predictions can be made.

1. Naming patches of color in English vs, the same task in French (Cell 3 vs. Cell 6) - dominance in English means that it should take less time to name patches of color in English than in French. Therefore, Cell 3 should have a lower time score than cell 6 .

2. Usual interference in the color naming subsystem by the word reading subsystem when both are functioning in the same language (Cell 1 vs. $\operatorname{Cell} 3$, and Cell 5 vs. Cell 6) - dominant bilinguals should show the same pattern as the "balanced" bilinguals; that is, Cells 1 and 5 should show greater time scores than Cells 3 and 6 respectively.

3. Response language English, interfering language English vs. response language English, interfering language French (Cell 1 vs. Cell 2) - the selective process should have 
an easier task in Cell 2 since response and interfering languages are different in that cell, while in Cell 1 they are the same. The task should also be easier in Cell 2 because it is assumed for French-English bilinguals dominant in English that the input process for words does not function as efficiently for words written in French as it does for words written in English. Since the word search process and the motor process function in English in both cells, these two factors should not contribute to differences between the two cells. Both relevant factors work in the same direction. Thus the prediction is that Cell 2 should have a lower time score than Cell 1.

4. Response language English, interfering language French vs。 response language French, interfering language French (Cell 2 vs. Cell 5) - since response and interfering languages are different in Cell 2 and the same in Cell 5, the selective process should function more efficiently in Cell 2. The input process for words functions in French in both cells and thus should not play a role in differ. ences between the two cells. Assuming that for FrenchEnglish bilinguals dominant in English the word search process and the motor process function more efficiently in English, these processes should function more efficiently in Cell 2 than in Cell 6 . All perating factors work in the same direction. The prediction is 
that Cell 2 should have a lower time score than cell 5 .

5. Response language English, interfering language French vs. response language French, interfering language English (Cell 2 vs. Cell 4) - differences between Cells 2 and 4 should not be affected by the selective process since in both cells response and interfering languages are different. However, the task in Cell 2 should be easier because the input process for words functions in French in Cell 2, while in Cell 4 it functions in English. In addition, the word search process and the motor process should also favor Cell 2 since they function in English in Cell 2 and French in Cell 4. All operating factors work in the same direction. The prediction is that cell 2 should have a lower time score than cell 4.

In the last three predictions the relevant factors work in opposite directions and thus a precise prediction would depend on a knowledge of the relative weights of the factors operating. For the predictions that follow, the motor process and the word search process have been assigned equal but considerably heavien weights than the input process for words and the selective process. These last two also have been weighted equally.

6. Response language English, interfering language English vs. response language French, interfering language French (Cell 1 vs. Cell 5) - the selective process should not play a role in this comparison since in both cells the response and interfering 
languages are the same. Cell 5 should be the easier task with respect to the input process for words, since in Cell 5 this process functions in French. On the other hand, Cell 1 should be the easier task with respect to the word search process and the motor process, since in cell 1 these two processes function in English. The relevant factors work in opposite directions. The input process for words tends to make Cell 5 have a lower score, while the word search process and the motor process tend to make cell 1 have a lower time score. If the word search process and the motor process are assigned heavier weights than the input process for words, then the prediction is that Cell 1 should have a lower time score than Cell 5.

7. Response language English, interfering language English vs. response language French, interfering language English (Cell 1 vs。Cell 4) - the selective process should favor cell 4 since response and interfering languages are different in that cell. The input process for words functions in English in both cells and therefore should not contribute to differences between the two cells. The word search process and the motor process should favor Cell 1 since they both function in English in Cell 1 and French in Cell 4. The relevant factors work in opposition. Assigning the motor process and the word search process heavier weights than the selective 
process, the prediction is that Cell 1 should have a lower time score than Cell 4.

8. Response language French, interfering language English vs. response language French, interfering language French (Cell 4 vs. Cell 5) - considering the selective process, the task should be easier in cell 4 since response and interfering languages are different in Cell 4. However, the input process for words should favor Cell 5, since this process functions in French in Cell 5. The word search process and the motor process should not contribute to differences between the cells since they function in French in both cases. The operating factors again work in opposing directions. Assigning equal weights to the relevant factors, the prediction is that cells 4 and 5 should have about the same time scores. In summary, Cell 2 should have a lower time score than Cells 1 , 4 and 5. Assigning the weights listed on page 21 to the various processes, Ceil I should have a lower time score than Cells 4 and 5. Finally, Ceils 4 and 5 should have approximately equal time scores. The predictions made in this chapter are primarily for time scores. In studies 1, 2 and 3, however, tape recordings made of the experimental sessions were examined to determine whether the errors made in performing the tasks followed the pattems predicted for the time scores. 
CHAPTER III

STUDY 1

This experiment was designed to test two predictions based on the proposed model of the color-word task. The model suggests that a selective process operates which attempts to reduce the interference in the color naming subsystem caused by the simultaneous operation of the word reading subsystem. It is assumed that the more similar the information being processed by these two subsystems, the more difficult the task of the selective process. According to this hypothesis, noncolor words should cause less interference than color words. In addition, the model suggests that the efficiency of a process increases with practice. According to this assumption, then, words of higher frequency should be handled more efficiently by the proposed input process for words than words of lower frequency. Thus words occurring infrequently in a language should cause less interference than those occurring frequently. The present experiment tested these two predictions 。 
METHOD

Subjects

Forty women college students served as $S$ s in this experiment. The maternal language of all $\underline{S}$ was English and their ages ranged from 18 to 22 years, with a mean age of 19.8 years. Each $\underline{S}$ was tested individually in the same room. The first 20 Ss were tested by the author and the other 20 Ss were tested by three undergraduate assistants。 Design

There were four main groups in the present experiment with ten Ss in each group. Ss in Group 1 named the colors of a series of blocks made from the letter X; Ss in Group 2 named the colors of low frequency non-color words; $\underline{S}$ in Group 3 named the colors of high frequency non-color words; Ss in Group 4 named the colors of color words (regular Card $\mathrm{C}$ ). Each color word had a corresponding non-color high frequency word, a non-color low frequency word, and a block of $X^{\prime}$. The color words and the high frequency non-color words were classified as $A A$, while the low frequency non-color words occurred less than 4 per million according to the Thorndike-worge word count (Thonndike $\varepsilon$ Lorge, 1944). Table 2 presents the words used。

One half of the $\underline{S}$ in each group was presented with three separate cards. On each card was a line of eight words, each word printed in one of the four colors: red, blue, green or brown. Each card had a different order of colors, each color appearing twice on a card. The other half of the $\underline{S}$ in each group were presented with a single card containing the same three lines presented separately to the first 
Table 2

Words Used in Study 1

\begin{tabular}{llll} 
Group 1 & Group 2 & Group 3 & Group 4 \\
\hline$X X X$ & CUR & CAR & RED \\
$X X X X$ & PITH & BIRD & BLUE \\
XXXXX & TRAWL & CHAIR & GREEN \\
XXXXX & REEVE & HOUSE & BROWN \\
& & & \\
\hline
\end{tabular}


half of the Ss. The separate cards - single card variation was introduced to examine the generality of the predictions.

The cards for Group 4 were made first. The words were arranged randomly with the restrictions that no word was ever followed by the same word and no word ever appeared in the color it denoted. The cards for Groups 1, 2 and 3 were then made by printing the appropriate corresponding word or block of $X^{\prime}$ 's in the same color. For instance, if the first word on a card in Group 4 was RED printed in blue ink, then the first item also printed in blue ink on the corresponding cards for Groups 1, 2 and 3 would be XXX, CUR and CAR respectively. All cards were produced on a typewriter with colored ribbons. There were four spaces between items and on the cards containing three lines, three spaces between each line. Appendix A.l presents the three line stimulus cards used in Study 1 .

Procedure

At the beginning of the testing session, the following instructions were read to $\underline{S}$ :

1. We will present to you a series of cards containing eight words. These words are printed in four different colors--blue, green, brown and red. (Ss were then shown a sample card with four blocks of $\bar{X}$ 's, each block printed in a different color, and asked to name the colors. The instructions were modified for $S s$ in the second half of each group.)

2. Your job is to name the color of the ink in which the words appear as fast as you can. Do not read the words. Start at the left and go to the right. I will place a piece of cardboard on top of the stimulus card. When I remove it, begin immediately. Do not wait for another signal.

3. Proceed as fast as you can without making a mistake。 


\footnotetext{
Enunciate clearly. If you make a mistake, correct it, but do not start over from the beginning of the list.

4. Is everything clear?
}

After the instructions were read, a stimulus card covered with a piece of cardboard was placed in front of $\underline{S}$. The watch was started when the cardboard was removed and stopped at the termination of the final response. Three separate time scores were obtained for the first five $\underline{S}$ s in each group, one for each card. One time score was obtained for the last five Ss in each group. The whole session was tape-recorded to permit an analysis of errors.

\section{RESULTS AND DISCUSSION}

Time scores

In each group the time scores on the three cards for the first five $\underline{S}$ were added together to obtain a total time score for each $\underline{S}$ for three lines. Table 3 presents the mean time scores to complete three lines for the two halves of each group as well as the overall mean time scores for each group. A two-way analysis of variance (Winer, 1962, p. 233) was applied with groups as one variable and three lines done separately vs. together as the other variable (see Appendix A.2). Both the group effect and the separate-together effect were significant at the .01 level. while the interaction was not significant. The NewmanKeuls procedure for multiple comparisons (Winer, 1962, pp. 211, 239) was applied across groups to the overall mean time scores as well as the mean time scores for the two halves. In Table 3 any two means that are underscored by the same line are not significantly different. Any 
Table 3

\author{
Mean Time Scores in Seconds to Complete Three Lines \\ for the Two Halves of Each Group as Well as the \\ Overall Mean Time Scores for Each Group \\ $(N=40)$
}

$\begin{array}{cccc}\text { Group 1 } & \text { Group 2 } & \text { Group 3 } & \text { Group 4 } \\ \text { Blocks } & \text { Low fre- } & \text { High fre- } & \text { High fre- } \\ \text { of X's } & \text { quency non- } & \text { quency non- } & \text { quency } \\ & \text { color words } & \text { color words } & \text { color words }\end{array}$

Three lines

done

separately

11.7

12.2

14.9

19.4

Three lines

done

together

12.5

14.6

16.4

24.1

Overall

12.1

13.4

15.6

21.8

Note.--Any two means underscored by a common line are not significantly different. Any two means not underscored by the same line differ significantly at the .05 level or better, Newman-Keuls procedure for multiple comparisons. 
two means that are not underscored by the same line are significantly different at the .05 level or better.

The Newman-Keuls procedure showed that the overall means for blocks of X's and low frequency non-color words did not differ significantly. All other comparisons differed at the .05 level or better. For three lines done separately, blocks of X's, low frequency non-color words and high frequency non-color words did not differ from each other; however, they all differed at the .05 level or better from high frequency color words. For three lines done together, blocks of X's and low frequency non-color words did not differ nor did low frequency non-color words and high frequency non-color words; all other comparisons were significant at the .05 level or better.

The results presented in Table 3 clearly confirm the prediction that non-color words are less interfering than color words. This effect cannot be attributed to differences in familiarity since the two sets of words were matched on frequency. The results also show for the overall means that even though high frequency non-color words are less interfering than color words, high frequency non-colon words cause significantly more interference than blocks of $X^{\prime}:$.

The hypothesis dealing with the effects of frequency received moderate support. The difference between the overall means for high and Low frequency non-color words was significant. For the two halves, the means on this comparison were in the expected direction but did not differ significantly. Additional support for this hypothesis lies in the fact that there was no significant difference in overall mean time scores between blocks of X's and low frequency non-color words, while the 
difference between the overall means for blocks of $X$ 's and high frequency non-color words was significant.

Error Scores

An analysis of the errors made by Ss while going through their cards was carried out using the categories listed in Table 4. Table 5 presents the total number of errors made in the eight subgroups. Since the number of errors was small, no statistical tests were applied, and only the total numbers are given. Table 6 presents the overall frequency of the different types of errors. Table 5 shows that the two high frequency color word groups tended to make more errors than the other groups. Table 6 shows that non-linguistic errors are the most frequent, followed by card interference errors (pronunciation of the printed word) which, it is important to note, occurred only in the two color word subgroups.

If sheer number of errors is taken as an indication of interterence, the error analysis supports the hypcthesis that non-color words are less interfering than color words. However, the error analyis lends little support to the hypothesis that low frequency words cause Less interference than high frequency words. In general, both time and error analyses suggest that variation in the frequency of the words has a minor effect on interference in the color naming subsystem. A more marked effect can be produced by the color word - non-color word variation. 
Table 4

Classification of Errors

1. Non-linguistic utterances. This category included uh's, um's, ah's and any other similar non-1inguistic sound produced during the test interval.

2. Card interference error. This error consisted of either a complete or partial pronunciation of the written word with or without correction

3. Wrong response error. This error consisted of either a complete or partial pronunciation with or without correction of some non-correct response other than the written word。

4. Repeat. This category consisted of a complete or partial pronunication of the correct response preceding the correct response

5. Other errors. Infrequent errors such as skipping an item or making a verbal comment were classified in this category. In Study 1 there were three errors in this category: one skip and two comments. 
Table 5

Total Number of Errors Made in Each of the Eight Subgroups

\begin{tabular}{llll}
$\begin{array}{l}\text { Blocks } \\
\text { of X's }\end{array}$ & $\begin{array}{l}\text { Low fre- } \\
\text { quency non- } \\
\text { color words }\end{array}$ & $\begin{array}{l}\text { High fre- } \\
\text { quency non- } \\
\text { color words }\end{array}$ & $\begin{array}{l}\text { High fre- } \\
\text { quency } \\
\text { color words }\end{array}$ \\
\hline
\end{tabular}

Three lines

done

separately

3

1

7

10

Three lines

done

together

0

2

2

26

Table 6

Distribution of Errors Made in All Groups

$\begin{array}{lc}\begin{array}{l}\text { Non-linguistic } \\ \text { Card interference, } \\ \text { corrected and } \\ \text { uncorrected }\end{array} & 16 \\ \begin{array}{l}\text { Wrong response, } \\ \text { corrected and } \\ \text { uncorrected }\end{array} & 7 \\ \text { Repeat } & 5 \\ \text { Other } & 3 \\ \text { TOTAL } & 51\end{array}$


CHAPTER IV

STUDIES 2 AND 3

The two studies in this section deal with some experiments with "balanced" bilinguals. In Chapter II it was predicted that color naming would suffer relatively less interference from word reading when these two sets of processes functioned in different languages and relatively more interference when they functioned in the same language。 This prediction follows from the assumption that a selective process which attempts to "gate out" the word reading subsystem works more efficiently when response and interfering languages are different。 other processes proposed in the model (input process for words, word search process and motor process) should not contribute to differences between the cells in Table 1 because it is assumed that these processes function equally well in both languages for "balanced" bilinguals. If Penfield's bilingual switch hypothesis is correct, there should be no difference between cells 2 and 3 , or cells 4 and 6 . Several variations were introduced to test the generality of the above predictions. In Study 2, there were two groups of bilinguals: 
English-Hungarian and English-French. In Study 3 there were two groups of English-German bilinguals. In one of the English-German groups, the color words used had translations with similar stimulus characteristics; in the other group, the color words had translations with different stimulus characteristics. The experimenters (one for each study) were undergraduate assistants 。

\section{METHOD (Study 2)}

\section{Subjects}

Eight English-French $(E-F)$ and eight English-Hungarian (E-H) bilinguals served as $\underline{S}$. The bilinguals employed were all highly recommended as fluent in both languages by friends who knew them well in both of their languages. A difference in the performance on Card $B$ in the two languages should, according to the proposed model, reflect the relative efficiencies of the word search process and the motor process. Thus a bilingual who takes longer to name the colors of patches in French than in English should possess a word search process and a motor process that function more efficiently in English than in French. Following this reasoning a perfectly "balanced" bilingual should take no more time to complete Card $B$ in one of his languages than in the other. In addition, a perfectly "balanced" bilingual should also possess an input process for words that functions equally well in both languages. Since the Ss employed in this experiment had no histories which indicated predominantly more reading in one of their two languages, it seems reasonable to assume that if a group showed no difference in performance on Card $B$ in the two languages and if the mean absolute difference on Card B was small, then the group as a whole could be considered "balanced". 
The mean difference between the two languages on Card $B$ was 0.5 seconds for $E-H \underline{S}$ s and 1.0 seconds for E-F Ss. These means did not differ significantly from 0 . The mean absolute difference on Card B was 9.3 and 6.6 seconds for $E-H$ and $E-F$ Ss respectively.

Seven E-H bilinguals were students at McGill University and one was a secretary. Six E-F bilinguals were McGill students, one was a nurse and one was a secretary. There were four males and four females in each group. The mean age for $E-H$ bilinguals was 20.1 years and for E-F bilinguals 20.4 years. No $\underline{S}$ was color blind, as determined by the presentation of the Ishihara plate in Hebb (1958, p.26)。

\section{Materials}

Three forms of Card $C$ were prepared, one each in English, French and Hungarian. Each card had ten rows of ten words. The colors and words used on the English card were red, blue, green and brown. The French equivalents were rouge, bleu, vert and brun; the Hungarian equivalents were piros, kekk, zbld and barna. The same method and restrictions used in making up the cards in Study 1 were applied in Study 2. The cards were produced on a typewriter with colored ribbons with four spaces between words and three spaces between lines. Three other cards were also made up. These cards were similar to the cards with blocks of $x^{8} s$ in study 2 with the exception that asterisks were substituted for X's。 There was a corresponding asterisk card for each form of Card C. An asterisk of the appropriate color was typed for each letter but the same spacing between words and lines was preserved. Appendices $B_{0} 1, B_{0} 2, B_{0} 3$ and $B_{0} 4$ present examples of the English Card $c$, the French Card c, the Hungarian Card $C$ and the English Cand B respectively. 


\section{Design and Procedure}

Each $S$ performed the following six tasks:

1. Named the colors of English words in English

2. Named the colors of French or Hungarian words in English

3. Named the colors of asterisks in English

4. Named the colors of English words in French or Hungarian

5. Named the colors of French or Hungarian words in French or Hungarian

6. Named the colors of asterisks in French or Hungarian. In this experiment all Ss were presented with the asterisk cards before they performed the other four tasks. Half the Ss named the colors of the asterisk cards first in English and then in either French or Hungarian. For the other half, the order was reversed. Eight of the 24 possible combinations of the remaining four tasks were selected. On half of these eight combinations the English card was used first, followed by either the French or Hungarian card, while on the other four combinations this onder was reversed. Ss who nimed the asterisks finst in English ctarted with the English Card $C_{9}$ Ss who named the asterisks first in Frenci or Hungarian started with the French or Hungarian Card co Table $y$ outines the expenimental desien.

Ss were tested individually at home or at work. Before commencing with the testing, instructions (see Appendix B.5) were read to each S. After the instructions, the procedure followed was similar to Study 1. The whole testing session ras tape-recorded. 
Table 7

Order of Tasks for Ss in Study 2

Orders

\begin{tabular}{llllllllll} 
& 1 & 2 & 3 & 4 & 5 & 6 & 7 & 8 \\
\cline { 2 - 8 } & 6 & 6 & 6 & 6 & 3 & 3 & 3 & 3 \\
& 3 & 3 & 3 & 3 & 6 & 6 & 6 & 6 \\
Tasks & 5 & 5 & 2 & 2 & 1 & 1 & 4 & 4 \\
& 2 & 2 & 5 & 5 & 4 & 4 & 1 & 1 \\
& 1 & 4 & 4 & 1 & 5 & 2 & 2 & 5 \\
& 4 & 1 & 1 & 4 & 2 & 5 & 5 & 2 \\
\hline
\end{tabular}




\section{RESULTS (Study 2)}

\section{Time scores}

Since tape recordings of the whole session had been made, time scores were taken directly from the tape. The clock was started on the initiation of the first response and stopped on the termination of the final response. Mean time scores on the six tasks for both groups were calculated. Tables 8 and 9 present these mean time scores for $E \propto H$ and E-F Ss respectively.

The form in which the data are presented in Tables 8 and 9 suggest a two-way analysis of variance model with response language and card as the main factors. However, the predictions call for comparisons between almost all the cells within each table. For this reason, a oneway analysis of variance model with repeated measures on the same subjects (Winer, 1962, p. 111) was chosen. As an example, in this model the six cells in Table 8 are treated as one dimension (Tasks). A significant F for Tasks indicates that some of the cells differ significantly. Follow ing a significant $F$ for Tasks, the Newman-Keuls procedure for multiple comparisons (Winer, 1962, p。114) was applied. This method of analysis was also employed in Studies 3 and 4 .

Appendix B.6 presents for the time scores the results of two oneway analyses of variance described above for $E-H$ and $E-F$ Ss respectively。 In both cases the Task effect was significant at the .01 level. Following the analyses of variance, the Newman-Keuls multiple comparison procedure was applied. In Tables 8 and 9, a line connecting any two cells indicates no difference. Any two cells not connected with a line differ 
Table 8

Mean Time Scores in Seconds for E-H Bilinguals on the Six Tasks ${ }^{\text {a }}$

$$
(N=8)
$$

English Card C Hungarian Card C Asterisk Card

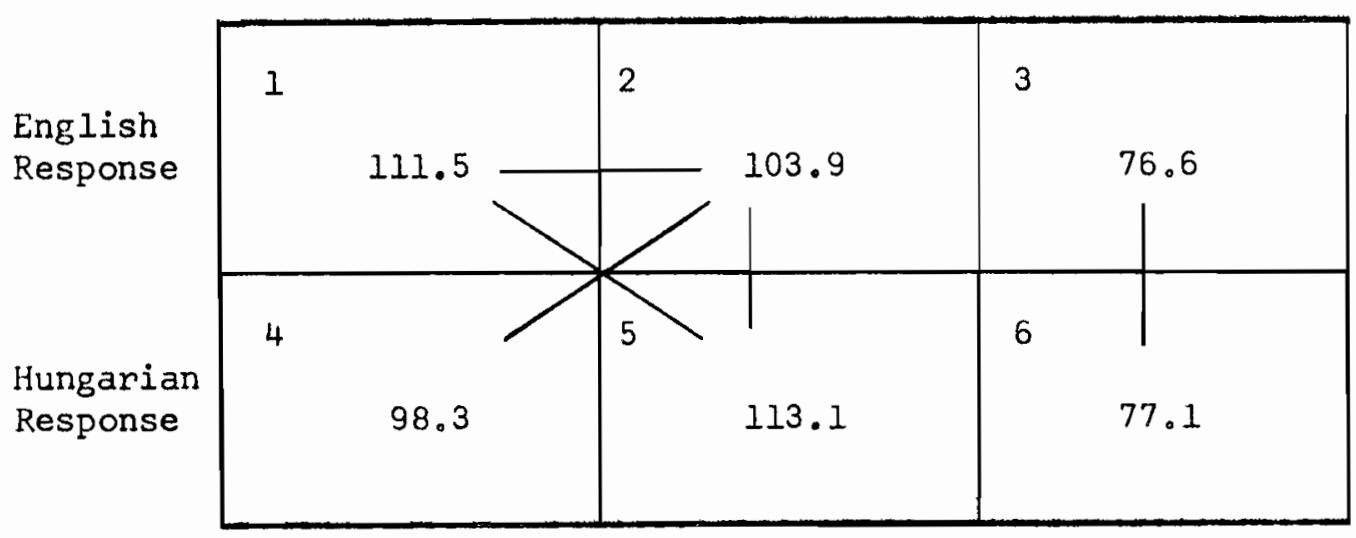

Table 9

Mean Time Scores in Seconds for E-F Bilinguals on the Six Tasks ${ }^{2}$

$$
(N=8)
$$

English Card C French Card C Asterisk Card

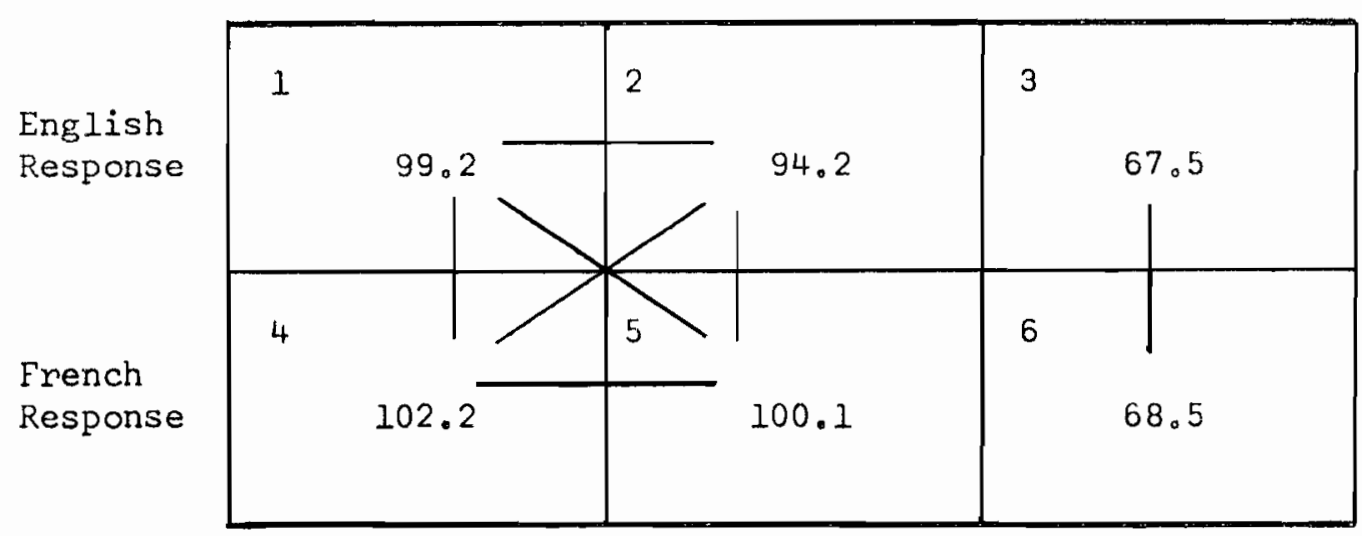

$a_{A}$ line connecting any two cells indicates no difference; any two cells not connected with a line differ at the .05 level or better, Newman-Keuls multiple comparison procedure. 
at the .05 level on better.

The following points summarize the results for E-H Ss:

1. There was no difference between the two languages on time to name the colors on the asterisk cards. Three Ss took more time in English, four Ss took more time in Hungarian, and one $\underline{S}$ took the same amount of time in each language.

2. The usual interference in color naming with words as the color bearing stimuli was replicated. This is shown by the significant differences between Cells 1 and 3 , and cells 5 and 6 . In addition, there is clearcut evidence that interference occurs even when response and interfering languages are different (significant differences between cells 2 and 3 , and Celis 4 and 6).

3. In general, as predicted, there was less interference when response and interfering languages were different compared to the case when they were the same. Thus, the means in Cells 2 and 4 were both lower than the means in Cells 1 and 5. However, the Newman-Keuls procedure indicated that only Celis 1 and 4 , and Cells 4 and 5 differed significantly. The following points summarize the results for E-F Ss:

1. There was no significant difference between the two asterisk tasks. Four Ss were faster in English and four Ss were faster in French.

2. Cells 1 and 2 differed from cell 3 , and Cells 4 and 5 
differed from cell 6. This finding is similar to Item 2 for E-H Ss.

3. The prediction that less interference would occur when response and interfering languages were different was not confirmed for E-Ss. The Newman-Keuls procedure showed no differences between Cells $1,2,4$ and 5 .

\section{Error scores}

The errors on the three forms of Card $C$ were divided into the following seven categories:

1. Non-linguistic utterances. This category included uh's, um's, ah's and any other similar non-linguistic sound produced during the test interval.

2. Card interference, correct response language, corrected. When response and interfering languages were the same, this error consisted of either complete or partial pronunciation of the printed word. When response and interfering languages were different, this error consisted of either a complete or partial pronunciation of the translated equivalent of the printed word. After the error a correction was made.

3. Card interference, correct response language, uncorrected。 This error was identical to the preceding type except that no correction was made.

4. Wrong response, correct response language, corrected. When response and interfering languages were the same, this error consisted of either a complete or partial 
pronunciation of some non-correct response in the correct response language other than the printed word. When response and interfering languages were different this error consisted of either a complete or partial pronunciation of some non-correct response in the correct response language other than the translation of the printed word. After the error a correction was made.

5. Wrong response, correct response language, uncorrected. This error was identical to the preceding type except that no correction was made.

6. Repeat. This error consisted of a complete or partial pronunciation of the correct response preceding the correct response.

7. Miscellaneous. This category consisted of infrequent types of errors. For $E-H$ and E-F Ss taken together there were ten verbal comments and two cases in which a response in the wrong language was given.

On the asterisk cards errors were categorized as follows:

1. Non-linguistic utterances. Same as Category 1 for the word cards.

2. Wrong response, correct response language, corrected. This error consisted of a partial or complete pronunciation of an incorrect response in the correct response language. After the error a correction was made.

3. Wrong response, correct response language, uncorrected. 
This error was identical to the preceding type except that a correction was not made.

4. Repeat. Same as Category 6 for the word interference cards.

5. Miscellaneous. Infrequent errors: four verbal comments and two skipped items.

Tables 10 and 11 present the per cent of total errors made on each of the six tasks for E-H and E-F bilinguals respectively. For both groups on the various forms of Card $C$, non-linguistic utterances were the most frequent. In general, card interference errors were more frequent than wrong response errors and corrected errors were more frequent than uncorrected errors. Repeat and miscellaneous errors were relatively infrequent. On the asterisk cards, there was no card interference classification. The most frequent errors were non-linguistic utterances and corrected wrong responses.

Tables 12 and 13 present the mean total errors on each of the six tasks for E-H and E-F bilinguals respectively. Two separate one-way analyses of variance similar to those used for the time scores were carried out (see Appendix B.7)。 In both groups, the Task effect was significant at the .05 level. However, the Newman-Keuls procedure showed no differences between any of the Tasks for E-H bilinguals. For E-F Ss, the only differences (.05 level) were between Cells 3 and 4 and Cells 4 and 6.

In the next four tables the total errors are broken down into linguistic and non-linguistic errors (utterances) where linguistic errors comprised all errors not classified as non-linguistic. Tables 
Table 10

Per cent of Total Errors on Each of the Six Tasks for E-H Ss

$(N=8)$

\begin{tabular}{|c|c|c|c|c|c|c|}
\hline Type of Error & $\begin{array}{l}\quad \text { English } \\
\text { English } \\
\text { Response } \\
\end{array}$ & $\begin{array}{l}\text { Card C } \\
\text { Hungarian } \\
\text { Response } \\
\end{array}$ & $\begin{array}{l}\text { Hungaria } \\
\text { English } \\
\text { Response } \\
\end{array}$ & $\begin{array}{l}\text { Cand C } \\
\text { Hungarian } \\
\text { Response } \\
\end{array}$ & $\begin{array}{l}\quad \text { Asteri } \\
\text { English } \\
\text { Response } \\
\end{array}$ & $\begin{array}{l}\text { sk Card } \\
\text { Hungar } \\
\text { Respon }\end{array}$ \\
\hline $\begin{array}{l}\text { Non-linguistic } \\
\text { utterances }\end{array}$ & 70 & 68 & 66 & 65 & 35 & 47 \\
\hline $\begin{array}{l}\text { Card interference, } \\
\text { correct response } \\
\text { language, corrected }\end{array}$ & 8 & 16 & 14 & 10 & -- & - \\
\hline $\begin{array}{l}\text { Card interference, } \\
\text { correct response } \\
\text { language, uncorrectea }\end{array}$ & 5 & 8 & 6 & 3 & -- & -- \\
\hline $\begin{array}{l}\text { Wrong response, } \\
\text { correct response } \\
\text { language, corrected }\end{array}$ & 7 & 5 & 9 & 12 & 43 & 29 \\
\hline $\begin{array}{l}\text { Wrong response, } \\
\text { correct response } \\
\text { language, uncorrected }\end{array}$ & 5 & 0 & 2 & 5 & 6 & 13 \\
\hline Repeat & 2 & 3 & 1 & 4 & 11 & 3 \\
\hline Miscellaneous & 3 & 0 & 2 & 1 & 5 & 8 \\
\hline Total $(\%)$ & 100 & 100 & 100 & 100 & 200 & 100 \\
\hline Total Number of Errors & 88 & 62 & 88 & 73 & 37 & 38 \\
\hline
\end{tabular}


Table 11

Per cent of Total Errors on Each of the Six Tasks for E-E Ss

$(N=8)$

\begin{tabular}{|c|c|c|c|c|c|c|}
\hline Type of Error & $\begin{array}{l}\quad \text { English } \\
\text { English } \\
\text { Response } \\
\end{array}$ & $\begin{array}{l}\text { Card } C \\
\text { French } \\
\text { Response } \\
\end{array}$ & $\begin{array}{l}\quad \text { French } \\
\text { English } \\
\text { Response } \\
\end{array}$ & $\begin{array}{l}\text { Card C } \\
\text { French } \\
\text { Response } \\
\end{array}$ & $\begin{array}{l}\text { Asteris } \\
\text { English } \\
\text { Response } \\
\end{array}$ & $\begin{array}{l}\text { Card } \\
\text { French } \\
\text { Response } \\
\end{array}$ \\
\hline $\begin{array}{l}\text { Non-linguistic } \\
\text { utterances }\end{array}$ & 50 & 48 & 46 & 60 & 18 & 57 \\
\hline $\begin{array}{l}\text { Card interference, } \\
\text { correct response } \\
\text { language, corrected }\end{array}$ & 27 & 32 & 26 & 25 & -- & -- \\
\hline $\begin{array}{l}\text { Card interference, } \\
\text { correct response } \\
\text { language, uncorrected }\end{array}$ & 4 & 7 & 9 & 2 & - & - \\
\hline $\begin{array}{l}\text { Wrong response, } \\
\text { correct response } \\
\text { language, corrected }\end{array}$ & 10 & 7 & 9 & 7 & 46 & 27 \\
\hline $\begin{array}{l}\text { Wrong response, } \\
\text { correct response } \\
\text { language, uncorrected }\end{array}$ & 0 & 1 & 0 & 0 & 24 & 5 \\
\hline Repeat & 8 & 3 & 9 & 4 & 9 & 11 \\
\hline Miscellaneous & 1 & 2 & 1 & 2 & 3 & 0 \\
\hline Total $(\%)$ & 100 & 100 & 100 & 100 & 100 & 100 \\
\hline Total Number of Errors & 78 & 107 & 81 & 90 & 33 & 37 \\
\hline
\end{tabular}


Table 12

Mean Total Errors on the Six Tasks for E-H Ss $(N=8)$

\begin{tabular}{|c|c|c|c|}
\hline & English Card $C$ & Hungarian Card C & Ast erisk Card \\
\hline English & 11.00 & 11.00 & 4.63 \\
\hline $\begin{array}{l}\text { Hungarian } \\
\text { Response }\end{array}$ & 7.75 & 9.13 & 4.75 \\
\hline
\end{tabular}

Note.--There were no significant differences between any of the cells using the Newman-Keuls test.

Table 13

Mean Total Errors on the Six Tasks for E-F Ss

$$
(N=8)
$$

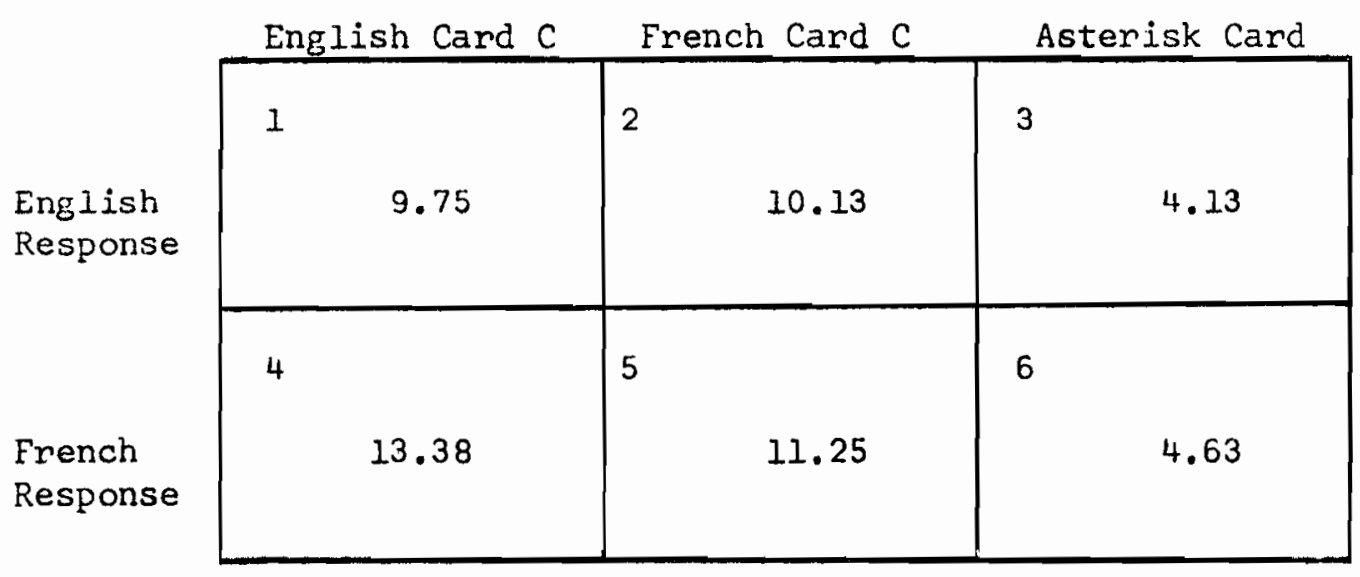

Note.--Significant differences between Cells 3 and 4, and Cells 4 and 6 only, Newman Keuls test, .05 level. 
14 and 15 present the mean non-linguistic errors for E-H and E-F bilinguals respectively. For the E-H bilinguals three of the eight Ss accounted for $96 \%$ of all non-linguistic errors while for the E-F bilinguals two Ss accounted for $79 \%$ of all the non-linguistic errors. For this reason no statistical analysis was done.

Tables 16 and 17 present the mean linguistic errors for E-H and E-F bilinguals respectively. Two one-way analyses of variance showed a significant Task effect (.01 level) for E-F Ss only (see Appendix B.8). The Newman-Keuls procedure for $E-F$ Ss indicated that Cell 6 differed from cells 1, 2 and 4, and that cell 3 differed from Cel1 4 (.05 level or better). Tables 18 and 19 present the mean number of card interference, correct response language errors for $E-H$ and $E-F$ Ss respectively. These means include both corrected and uncorrected errors. The two one-way analyses of variance showed no significant Task effect for either group (see Appendix B.9).

\section{DISCUSSION (Study 2)}

The results for time scores make it clear for "balanced" bilinguals that interference in color naming when words are the color bearing stimuli occurs even when the response language differs from the language of the words. This effect, noted for both $\mathrm{E}-\mathrm{H}$ and $\mathrm{E}-\mathrm{F}$ Ss, is shown in Tables 8 and 9 by the significant differences between Cells 2 and 3 , and cells 4 and 6 . This finding lends little support to Penfield's notion of a bilingual switch.

The prediction based on the proposed model that less interference in color naming wolld occur when response language and interm fering language were different compared to the situation in which the 
Table 14

Mean Non-linguistic Errors on the Six Tasks for E-H Ss

$(N=8)$

\begin{tabular}{|c|c|c|c|}
\hline & English Card C & Hungarian Card C & Asterisk Card \\
\hline $\begin{array}{l}\text { English } \\
\text { Response }\end{array}$ & 1 & 2 & 1.63 \\
\hline $\begin{array}{l}\text { Hungarian } \\
\text { Response }\end{array}$ & 4 & 5 & 2.25 \\
\hline
\end{tabular}

Table 15

Mean Non-linguistic Errors on the Six Tasks for E-F Ss

$$
(\mathrm{N}=8)
$$

English Card C French Card C Asterisk Card

French Response

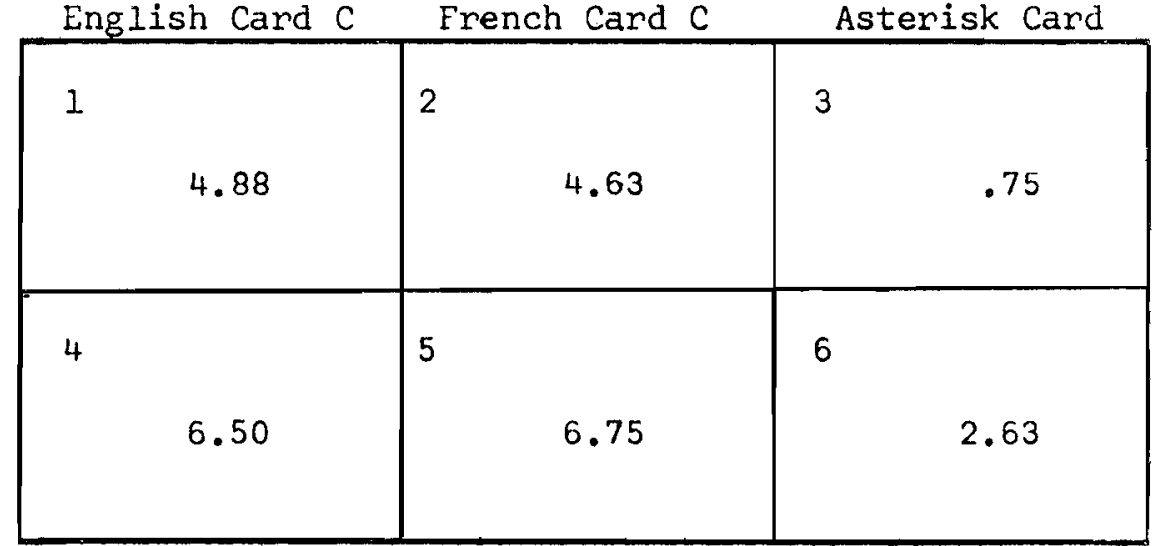


Table 16

Mean Linguistic Errors on the Six Tasks for E-H Ss

$(\mathrm{N}=8)$

English Card C Hungarian Card C Asterisk Card

\begin{tabular}{|c|c|c|c|}
\hline $\begin{array}{l}\text { English } \\
\text { Response }\end{array}$ & 1 & 2 & 3.00 \\
\hline $\begin{array}{l}\text { Hungarian } \\
\text { Response }\end{array}$ & 4 & 5 & 2.50 \\
\hline
\end{tabular}

Note.--There were no significant differences between any of the cells, one-way analysis of variance for repeated measures.

Table 17

Mean Linguistic Errors on the Six Tasks for E-F Ss

$$
(N=8)
$$

\begin{tabular}{|c|c|c|c|}
\hline & English Card C & French Card C & Asterisk Card \\
\hline $\begin{array}{l}\text { English } \\
\text { Response }\end{array}$ & $\perp$ & 2 & 3.38 \\
\hline $\begin{array}{l}\text { French } \\
\text { Response }\end{array}$ & $\begin{array}{l}4 \\
6.88\end{array}$ & 5 & 2.00 \\
\hline
\end{tabular}

Note.--Cell 6 differed from Cells 1, 2 and 4, and Cell 3 differed from Cell 4, Newman-Keuls test, .05 level. 
Table 18

Mean Number of Card Interference, Correct Response Language Errors on the Four Word Cards for $\mathrm{E}-\mathrm{H}$ Bilinguals (Corrected and Uncorrected Errors Combined)

$(N=8)$

English

Response

Hungarian

Response

\begin{tabular}{|ll|lc|}
\hline \multicolumn{1}{|c|}{ English Card C } & Hungarian Card C \\
\hline 1 & 1.38 & 2 & \\
\hline 4 & & 5 & \\
& 1.88 & & 1.13 \\
\hline
\end{tabular}

Note.--There were no significant differences between any of the cells, one-way analysis of variance for repeated measures.

Table 19

Mean Number of Card Interference, Correct Response Language Errors on the Four Word Cards for E-F Bilinguals (Corrected and Uncorrected Errors Combined)

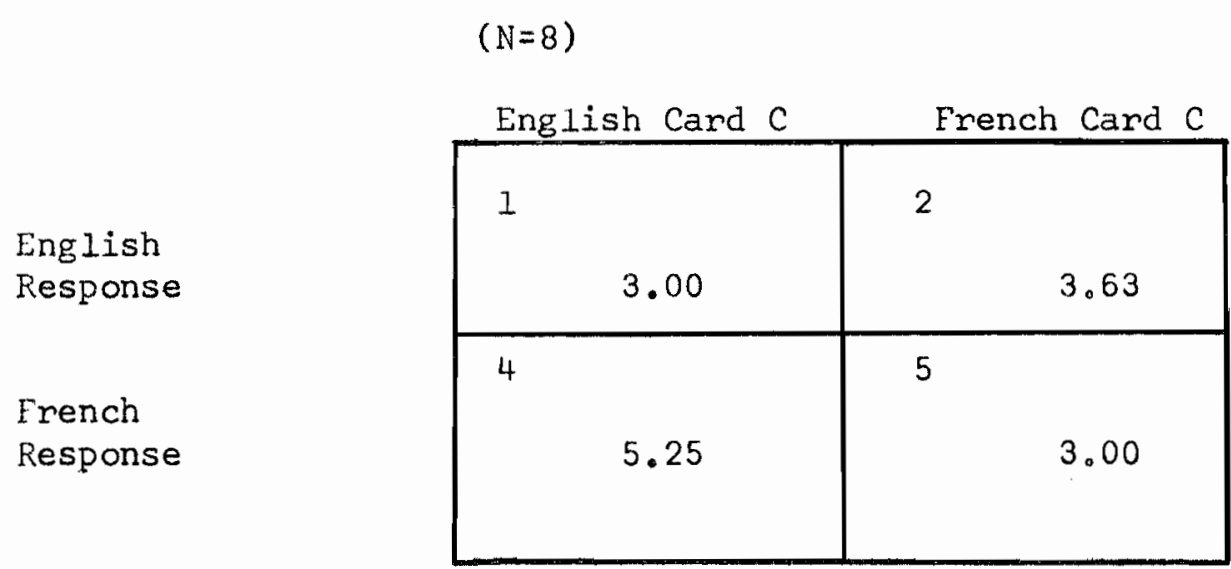

Note.--There were no significant differences between any of the cells, onewway analysis of variance for repeated measures. 
two languages were the same found moderate support in the pattern of time scores for E-H Ss but not for E-F Ss. In Table 8, the means in Cells 2 and 4 were both lower than the means in Cells 1 and 5 for E-H Ss and the Newman-Keuls procedure indicated that Cells 1 and 4, and Cells 4 and 5 differed significantly. For E-F Ss, Cells 1, 2, 4 and 5 in Table 9 did not differ significantly。

The error analysis provided no support for the Penfield notion on the above prediction for either E-H or E-F SS. For both groups, there were no significant differences between Cells $1,2,4$ and 5 for total errors, linguistic errors or card interference errors, The instructions were to proceed as fast as possible without making errors. To go very fast would have meant making many errors; on the other hand, by going very slowly all errors could have been avoided completely. Since neither of these two possibilities was called for by the instructions, Ss had to adopt a compromise between these two extremes. One possibility is that $\underline{S}$ adopted the strategy of making roughly the same number of errors on the word cards at the fastest possible speed. Apparently E-H Ss could go a little faster when response and interfering languages were different without increasing the number of errors. It is interesting to note that $S$ s rarely gave a response in the inappropriate language. When response and interfering languages were different, Ss occasionally responded with the translation of the printed word, suggesting that in this case word reading may interfere, in part, with color naming via a translation process. Following this reasoning, one difference between $E-H$ and $E-F$ SS that might account for the different patterns of time scores presented by these two groups is that 
three of the four French translations of the English color words had similar stimulus characteristics (bleu-blue, rouge-red, and brun-brown) while three of the four Hungarian translations had different stimulus characteristics (kék-blue, zöldegreen, and piros-red). Interference in color naming in cells 2 and 4 may be more likely when the color words employed have translations with similar stimulus characteristics. study 3 examined this possibility。

\section{METHOD (Study 3)}

$\underline{\text { Subjects }}$

Sixteen English-German bilinguals, divided into two groups, served as SS. All Ss were undergraduate students at McGill University。 Their ages ranged from 19 to 25 years with a mean of approximately 21 . The mother tongue of all Ss was German. The average age at which they had learned English was 10 years. All Ss used German at home and English at the Univensity. Thus, at the time of testing they were in contact with both languages. None of the Ss were color-blind, as determined by the presentation of the Ishihara plate in Hebb $(1958, p, 26)$. The mean difference between the two languages on Card $B$ was 1.1 seconds for Group 1 and 1.6 seconds for Group 2. The mean absolute difference for Card B was 5.8 and 8.4 seconds for Groups 1 and 2 respectively。

\section{Materials}

Two sets of cards, each caxd containing fifty stimuli arranged in Eive rows of ten, were hand-printed in two different sets of colors. Set 1 used the colors green, red, blue and brown; set 2 used black, yeliow, pink and purple. Two forms of Card B, two English forms of Card 
C, and two German forms of Card C were prepared for each color set. The same method and restrictions used in making up the cards in Study 2 were employed in this Study, In set 1 the English color words were green, red, blue and brown, while the German color words were griln, rot, blau and braun. In set 2 the color words were black, yellow, pink, and purple in English and schwarz, gelb, rosa and lila in German. Translated equivalents in the two languages look and sound more similar in Set 1 than in Set 2, especially on the initial phonemes. Wavy lines instead of asterisks were used on the two forms of Card B.

Design and procedure

The 16 Ss were divided equally into two groups with two males and $\operatorname{six}$ females in each group. Group 1 was tested with Set 1 cards, Group 2 was given Set 2 cards. Each $\underline{S}$ performed the six tasks described on page 33, with the exception that German was substituted for French or Hungarian. A design identical to the one in Study 2 was employed. Form 2 of each card always followed presentation of Form 1.

Each $S$ was tested individually in the same experimental room. Before each test session was a short interview during which $\underline{E}$ questioned $\underline{S}$ both in English and German about $\underline{S}^{\prime} s$ use of his two languages in various situations. Following the interview, instructions similar to those in Study 2 were given. Before the presentation of each card, $\underline{S}$ was always instructed in the same language in which he was asked to respond. The complete test session was tape-recorded. Time and error scores were taken directly from the tape after the experimental session. 


\section{RESULTS (Study 3)}

\section{Time scores}

An analysis similar to Study 2 was employed. The mean time scores (per 100 items) are presented in Tables 20 and 21 for Groups 1 and 2 respectively. The same one-way analyses of variance used in Study 2 were carried out (see Appendix B.10). For both groups, the Task effect was significant at the .0I level. Comparisons between the means in each group were made using the Newman-Keuls procedure. In Tables 20 and 21, a line joining any two cells indicates no significant difference; any two cells not joined by a line are significantly different from each other (.05 level or better).

The following points summarize the results for both groups:

1. There was no difference between cells 3 and 6 in either group. Thus the two groups as a whole could be considered "balanced".

2. In both groups Cells 1 and 2 differed from Cell 3, and Cells 4 and 5 differed from Cell 6, suggesting as in study 2 that interference in color naming takes place even when response and interfering languages are different.

3. In Group 1, Cells 1, 2, 4 and 5 did not differ from each other, which suggests that the amount of interference experienced by Group $I$ is the same in these four cells.

4. In Group 2, interference tended to be less when response and interfering languages were different, that is Cells 2 and 4 showed lower time scores than cells 1 and 5. However, the Newman-Keuls procedure indicated that 
Mean Time Scores in Seconds for the Six Tasks in Group $1^{\text {a }}$ $(N=8)$

\begin{tabular}{|c|c|c|c|c|}
\hline & English Card $C$ & German Card C & Wavy & line Card \\
\hline $\begin{array}{l}\text { English } \\
\text { Response }\end{array}$ & $\begin{array}{l}1 \\
100.8\end{array}$ & 101.6 & 3 & 65.5 \\
\hline $\begin{array}{l}\text { German } \\
\text { Response }\end{array}$ & 105.2 & 99.7 & 6 & 66.6 \\
\hline
\end{tabular}

Table 21

Mean Time Scores in Seconds for the Six Tasks in Group $2^{a}$

$$
(N=8)
$$

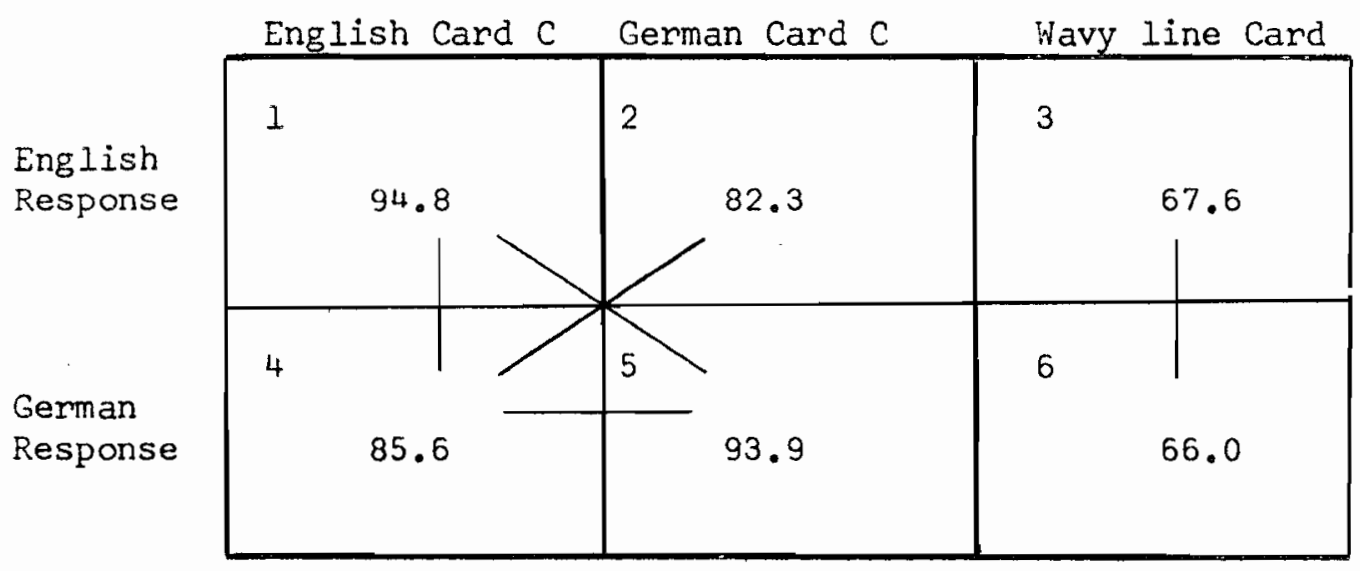

${ }^{a} \mathrm{~A}$ line connecting any two cells indicates no difference; any two cells not connected with a line differ at the .05 level or better, Newman-Keuls multiple comparison procedure. 
only Cells 1 and 2 , and Cells 2 and 5 differed significantly.

\section{Error scores}

An aralysis of errors using the same caregories employed in Study 2 was carried out. Tables 22 and 23 present the per cent of total errors on each of the six tasks for both groups. In comparing Tables 22 and 23 with Tables 10 and 11, the same general picture emerges. Nonlinguistic utterances occurred most frequently. Card interference errors were more frequent than wrong response errors and corrected errors were more frequent than uncorrected errors. Repeat and miscellaneous errors were relatively infrequent. In the miscellaneous category, there were two omissions and six cases in which the incorrect response language was used. On the wavy line cards, the most frequent errors were non-1inguistic utterances and wrong responses.

Tables 24 and 25 present the mean total errors for Groups 1 and 2 respectively. Two one-way analyses of variance yielded $F$ values for Tasks significant at the .05 level for both groups (see Appendix B.11)。 Fon Group 1, the Newman-Keuls procedure showed that only Cells 3 and 4 differed significantly. For Group 2, Cell 5 differed significantly from Cells 3 and 6 . Tables 26 and 27 present the mean non-linguistic errors (utterances) for Groups 1 and 2 respectively. As in Study 2, a few Ss accounted for the majority of non-linguistic errors: two Ss in Group 1 accourted for $73 \%$, and $1 \underline{S}$ in Group 2 accounted for $69 \%$ of these errors. Tables 28 and 29 present the mean linguistic errors for Groups 1 and 2 respectively. One-way analyses of variance did not yield sig nificant Task effects for either group (see Appendix B.12)。Finally 
Table 22

Per cent of Total Errors on. Each of the Six Tasks for Group 1

$(y=8)$

\begin{tabular}{|c|c|c|c|c|c|c|}
\hline Type of Error & $\begin{array}{l}\quad \text { English } \\
\text { English } \\
\text { Resoonse } \\
\end{array}$ & $\begin{array}{l}\text { Card C } \\
\text { German } \\
\text { Response } \\
\end{array}$ & $\begin{array}{l}\quad \text { German } \\
\text { English } \\
\text { Resoonse } \\
\end{array}$ & $\begin{array}{l}\text { Card } C \\
\text { German } \\
\text { Response } \\
\end{array}$ & $\begin{array}{l}\text { Vavy lin } \\
\text { English } \\
\text { Response } \\
\end{array}$ & $\begin{array}{l}\text { Card } \\
\text { German } \\
\text { Response } \\
\end{array}$ \\
\hline $\begin{array}{l}\text { Non-linguistic } \\
\text { utterances }\end{array}$ & 49 & 48 & 46 & 56 & 49 & 44 \\
\hline $\begin{array}{l}\text { Card interference, } \\
\text { correct response } \\
\text { language, corrected }\end{array}$ & 20 & 26 & 24 & 19 & - & -- \\
\hline $\begin{array}{l}\text { Card interference, } \\
\text { comect response } \\
\text { language, uncorrected }\end{array}$ & 3 & 7 & 0 & 6 & - & -- \\
\hline $\begin{array}{l}\text { Wrong response, } \\
\text { conrect response } \\
\text { Lamguage, corrected }\end{array}$ & 2 & 4 & 13 & 7 & 21 & 42 \\
\hline $\begin{array}{l}\text { Trong response, } \\
\text { correct response } \\
\text { langliage, uncorrected }\end{array}$ & 3 & 1 & 0 & 1 & 18 & 7 \\
\hline Repeat & 22 & 12 & 14 & 11 & 12 & 7 \\
\hline Uisceilaneous & 1 & 2 & 3 & 0 & 0 & 0 \\
\hline Total $(\%)$ & 100 & 100 & 100 & 100 & 100 & 100 \\
\hline Total Number of Errors & 65 & 81 & 55 & 73 & 33 & 45 \\
\hline
\end{tabular}


Table 23

Per cent of Total Errors on Each of the Six Tasks for Group 2

$(N=8)$

\begin{tabular}{|c|c|c|c|c|c|c|}
\hline Type of Error & $\begin{array}{l}\quad \text { English } \\
\text { English } \\
\text { Response } \\
\end{array}$ & $\begin{array}{l}\text { Card C } \\
\text { German } \\
\text { Response } \\
\end{array}$ & $\begin{array}{l}\quad \text { German } \\
\text { English } \\
\text { Response } \\
\end{array}$ & $\begin{array}{l}\text { Card C } \\
\text { German } \\
\text { Response } \\
\end{array}$ & $\begin{array}{l}\text { Wavy lin } \\
\text { English } \\
\text { Response } \\
\end{array}$ & $\begin{array}{l}\text { Card } \\
\text { German } \\
\text { Response } \\
\end{array}$ \\
\hline $\begin{array}{l}\text { Non-linguistic } \\
\text { utterances }\end{array}$ & 53 & 40 & 65 & 53 & 31 & 13 \\
\hline $\begin{array}{l}\text { Card interference, } \\
\text { correct response } \\
\text { language, corrected }\end{array}$ & 25 & 16 & 11 & 16 & -- & -- \\
\hline $\begin{array}{l}\text { Card interference, } \\
\text { correct response } \\
\text { language, uncorrected }\end{array}$ & 2 & 2 & 2 & 5 & - & -- \\
\hline $\begin{array}{l}\text { Wrong response, } \\
\text { correct response } \\
\text { language, corrected }\end{array}$ & 9 & 26 & 18 & 12 & 65 & 67 \\
\hline $\begin{array}{l}\text { Wrong response, } \\
\text { correct response } \\
\text { language, uncorrected }\end{array}$ & 0 & 0 & 0 & 5 & 0 & 8 \\
\hline Repeat & 11 & 12 & 4 & 7 & 4 & 12 \\
\hline Miscellaneous & 0 & 4 & 0 & 2 & 0 & 0 \\
\hline Total $(\%)$ & 100 & 100 & 100 & 100 & 100 & 100 \\
\hline Total Number of Errors & 56 & 50 & 45 & 76 & 23 & 24 \\
\hline
\end{tabular}


Table 24

Mean Total Errors on the Six Tasks for Group 1

$$
(N=8)
$$

\begin{tabular}{|c|c|c|c|c|}
\hline & English Card & German Card 0 & Wavy & line Card \\
\hline $\begin{array}{l}\text { English } \\
\text { Response }\end{array}$ & 1 & 2 & 3 & 4.13 \\
\hline $\begin{array}{l}\text { German } \\
\text { Response }\end{array}$ & 10.13 & 9.13 & 6 & 5.63 \\
\hline
\end{tabular}

Note.--Significant differences between Cells 3 and 4 only, Newman-Keuls procedure, .05 level.

Table 25

Mean Total Errors on the Six Tasks for Group 2

$$
(\mathrm{N}=8)
$$

\begin{tabular}{|c|c|c|c|c|}
\hline & English Card C & German Card C & Wavy & Iine Card \\
\hline $\begin{array}{l}\text { English } \\
\text { Response }\end{array}$ & 1 & 2 & 3 & 2.88 \\
\hline $\begin{array}{l}\text { German } \\
\text { Response }\end{array}$ & 4 & 5 & 6 & 3.00 \\
\hline
\end{tabular}

Note.--Significant differences between Cells 3 and 5 , and Cells 5 and 6 only, Newman-Keuls procedure, .05 level, 
Table 26

Mean Non-linguistic Errors on the Six Tasks for Group 1 $(N=8)$

\begin{tabular}{|c|c|c|c|c|}
\hline & English Card C & German Card C & Wavy & line Card \\
\hline $\begin{array}{l}\text { English } \\
\text { Response }\end{array}$ & 1 & 2 & 3 & 2.00 \\
\hline $\begin{array}{l}\text { German } \\
\text { Response }\end{array}$ & 4.88 & 5 & 6 & 2.50 \\
\hline
\end{tabular}

Table 27

Mean Non-linguistic Errors on the Six Tasks for Group 2

$$
(N=8)
$$

\begin{tabular}{|c|c|c|c|c|}
\hline & English Card $\mathrm{C}$ & German Card C & Wavy & line Card \\
\hline $\begin{array}{l}\text { Eng I ish } \\
\text { Response }\end{array}$ & $I$ & 2 & 3 & .88 \\
\hline $\begin{array}{l}\text { German } \\
\text { Response }\end{array}$ & 4 & 5 & 6 & .38 \\
\hline
\end{tabular}


Table 28

Mean Linguistic Errors on the Six Tasks for Group 1

$$
(N=8)
$$

\begin{tabular}{|c|c|c|c|c|}
\hline & English Card C & German Card C & Wavy & line Card \\
\hline $\begin{array}{l}\text { English } \\
\text { Response }\end{array}$ & 1 & 2 & 3 & 2.13 \\
\hline $\begin{array}{l}\text { German } \\
\text { Response }\end{array}$ & 4 & 5 & 6 & 3.13 \\
\hline
\end{tabular}

Note.--There were no significant differences between any of the cells, one-way analysis of variance for repeated measures.

Table 29

Mean Linguistic Errors on the Six Tasks for Group 2

$$
(N=8)
$$

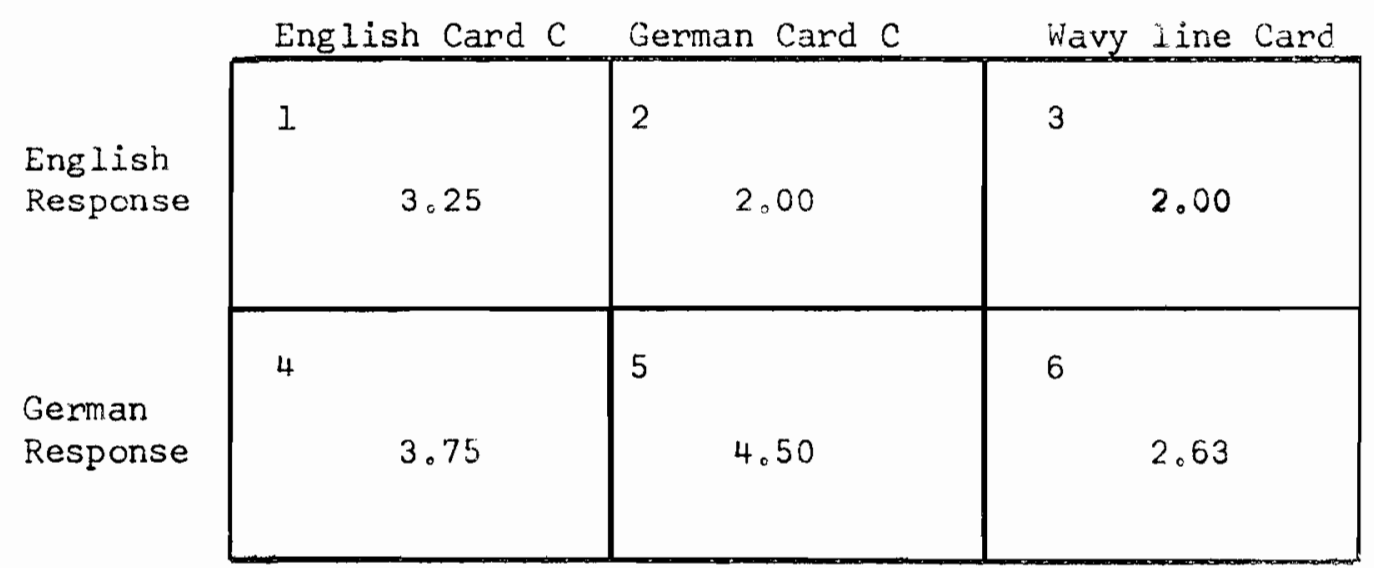

Note.-There were no significant differences between any of the cells, one-way analysis of variance for repeated measures. 
Table 30

Mean Number of Card Interference, Correct Response Language Errors on the Four Word Cards for Group 1 (Corrected and

$$
\text { Uncorrected Errors Combined) }
$$

$(N=8)$

\begin{tabular}{|c|c|c|}
\hline & English Card C & German Card C \\
\hline $\begin{array}{l}\text { English } \\
\text { Response }\end{array}$ & $\begin{array}{ll}1 & \\
& 1.88\end{array}$ & 1.63 \\
\hline $\begin{array}{l}\text { German } \\
\text { Response }\end{array}$ & 4 & 2.25 \\
\hline
\end{tabular}

Note.--There were no significant differences between any of the cells, one-way analysis of variance for repeated measures.

Table 31

Mean Number of Card Interference, Correct Response Language Errors on the Four Word Cards for Group 2 (Corrected and Uncorrected Errors Combined)

$(N=8)$

English

Response

German

Response

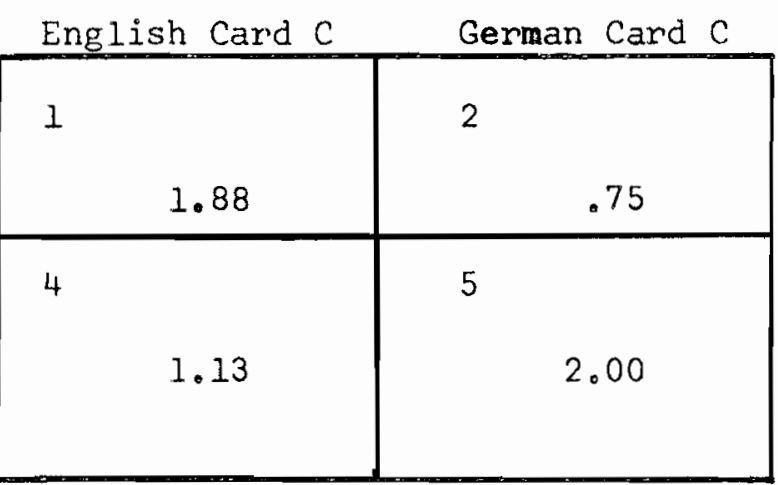

Note.--There were no significant differences between any of the cells, one-way analysis of variance for repeated measures. 
Tables 30 and 31 present card interference, correct response language errors for Groups 1 and 2 respectively. These last two tables include both corrected and uncorrected errors. One-way analyses of variance showed no significant Task effects in either group (see Appendix B.13)。

\section{DISCUSSION (Study 3)}

The results for the time scores for both groups of "balanced" English-German bilinguals again make it clear that color naming will suffer interference from printed words even when response and interfering languages are different. This is shown by the significant differences between Cells 2 and 3 , and Cells 4 and 6 in Tables 20 and 21.

The pattern of time scores for Group 2 followed the prediction of less interference when response and interfering languages were different and more interference when they were the same. This is shown in Table 21 by the lower time scores in Cells 2 and 4 compared to Cells I and 5. The Newman-Keuls procedure, however, indicated that only Cells I and 2 , and Cells 2 and 5 differed significantly。 Table 20 for Group 1 , showed no significant differences between Cells 1, 2, 4, and 5. The results of the error analysis were very similar to Study 2 . For both groups there were no significant differences between Cells 1, 2, 4, and 5 for total errors, linguistic errors or card interference errors.

In general, the results of Study 3 lend some support to the notion suggested earlier that less interference will occur when response and interfering languages are different if the translated equivalents of the color words employed have different stimulus characteristics. The effect, reflected in time scores only, appears to be a relatively mild one. 
CHAPTER V

STUDY 4

This chapter describes the results of some experiments with "dominant" bilinguals. The Ss in these experiments were native speakers of English with three or more years of training in French at Stanford University. All Ss took longer to name the colors on Card B in French than in English. From these observations, it seems reasonable to assume that for these Ss, the input process for words, the word search process and the motor process as proposed in the model all function more efficiently in English than in French.

Since these Ss could be classified as English-French bilinguals dominant in English, Predictions 3, 4, 5, 6, 7 and 8 in Chapter II for "dominant" bilinguals may be applied. In Predictions 3, 4 and 5, the relevant factors (processes) work in the same direction. These three predictions clearly suggest that in Table 1, Cell 2 will have a lower time score than Cells 1, 4 and 5. In Predictions 6, 7 and 8, the relevant factors work in opposing directions and thus depend on the weights assigned to them.

Rough estimates of these weights may be made from the results of Studies 1,2 and 3 , and also from the performance of $\underline{S}$ in the present study on Card B. Study I suggests that interference in color naming is only mildly affected by variation in the frequency of the interfering 
words. The time score for low frequency non-color words was approximately $14 \%$ lower than the time score for high frequency non-color words. Thus, it is likely that the input process for words will handle French words almost as efficiently as English words.

Studies 2 and 3 suggest that if the translated equivalents of the interfering words have different stimulus characteristics, color naming will suffer less interference from word reading when response and interfering languages are different compared to the situation when they are the same. By combining E-H Ss in Study 2 with Group 2 Ss in Study 3 (cell by cell), an estimate of the relative efficiency of the selective process in "gating out" the word reading subsystem when response and interfering languages are different may be obtained. Using this procedure it was found that the time scores for cells 2 and 4 were approximately $10 \%$ lower than the time scores for Cells 1 and 5. Since two of the four color words used in Study 4 had translated equivalents with similar stimulus characteristics, this effect may be even less pronounced in this study.

Performance on Card B suggests for the Ss in Study 4 that the relative efficiencies of the word search process and the motor process vary considerably depending on the response language. Ss in the first group took $38 \%$ more time to name the colors on Card B in French than in English. In the second group, Ss took $22 \%$ more time in French。 It is assumed, then, that the word search process and the motor process (which always operate in the same language and therefore in the same direction) carry more weight in determining differences between cells in Table 1 than the word search process or the selective process. Thus Cell I should have a lower time score than Cells 4 and 5 (Predictions 6 and 7 for "dominant" bilinguals, Chapter II). Finally, since the 
weights assigned to the selective process and the input process for words do not differ by very much ( $10 \%$ vs. $14 \%$ ), it is assumed that these two factors are equally weighted. Under this assumption, Cell 4 should not differ from Cell 5 in Table 1 (Prediction 8 for "dominant" bilinguals, Chapter II)。 Predictions 6, 7 and 8 are tentative since they make use of indirect estimates of the relative weights of the processes involved. Predictions 3,4 and 5, however, are straightforward since they do not depend on a knowledge of these weights.

In addition to performing the six tasks listed on page 33 , Ss also performed the following new tasks:

7. Named the colors of English non-color words in English.

8. Named the colors of French non-color words in English.

9. Named the colors of English non-color words in French.

10. Named the colors of French non-color words in French.

This variation was introduced to determine whether the same pattern of results obtained for color words would also be obtained for non-color words.

METHOD

Subjects

Eight undergraduates and eight graduate students at Stanford University served as $\underline{S}$ in the present study. Both groups were undertaking the study of French as a major subject. The undergraduates had a mean of 6.0 years training in French while the graduate students had a mean of 8.1 years. Originally, it was hoped that the graduate students would show relatively little difference in time scores on Card $B$ in the 
two languages. However, as indicated earlier, both groups took significantly longer to name the colors in French than in English. For undergraduates the mean difference on Card B was 23.1 seconds while for graduate students it was 16.1 seconds. Thus the predictions for both groups remained the same.

Materials

Two different forms of card $C$ for each of the following four types of stimuli were prepared:

1. English color words

2. French color words

3. English non-color words

4. French non-color words

The same method and restrictions employed in the other studies were used in preparing these cards. The English color words were red, brown, yellow, and green; the French equivalents were rouge, brun, jaune, and vert. The English non-color words were house, book, child, and kitchen; the French equivalents were maison, livre, enfant, and cuisine. In addition, two forms of Card $B$ were prepared using random sequences of the letters $\underline{a}, \underline{b}, \underline{c}$, and $\underline{d}$ instead of asterisks or wavy lines. Each card had five rows of ten stimuli. All cards were hand-printed.

$\underline{\text { Design and Procedure }}$

There were two groups of $\underline{S}$ (undergraduates and graduates) and the design was the same in each group. Ss performed the four new tasks listed on page 48 as well as the six tasks listed on page 33. All $\underline{\text { s }}$ worked on the two forms of Card B first. There were four pairs of $\underline{S}$ in each group. Table 32 presents, as an example, the order of presentation for one pain of Ss. Two pairs responded to Form 1 of Card B in both lang 
Order of Presentation for One Pair of Ss in Study 4

Response Language

\begin{tabular}{|c|c|c|c|}
\hline Sequence & Card & Member 1 & Member 2 \\
\hline 1. & Card $B, 1^{a}$ & English & French \\
\hline 2. & Card $B, I$ & French & English \\
\hline 3. & Card B, 2 & French & English \\
\hline 4. & Card B, 2 & English & French \\
\hline 5. & French color words, 1 & French & English \\
\hline 6. & English non-color words, 1 & English & French \\
\hline 7. & French non-color words, 2 & French & English \\
\hline 8. & English color words, 1 & English & French \\
\hline 9. & French non-color words, 1 & English & French \\
\hline 10. & English color words, 2 & French & English \\
\hline 11. & French color words, 2 & English & French \\
\hline 12 . & English non-color words, 2 & French & English \\
\hline 13. & English non-color words, 2 & French & English \\
\hline 14. & French color words, 2 & Eng 1ish & French \\
\hline 15。 & English color words, 2 & French & English \\
\hline 16. & French non-color words, 1 & English & French \\
\hline 17. & English color words, 1 & English & French \\
\hline 18. & French non-color words, 2 & French & English \\
\hline 19. & English non-color words, 1 & English & French \\
\hline 20. & French color words, 1 & French & English \\
\hline
\end{tabular}

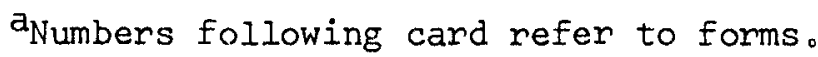


uages and then responded to Form 2. For the other two pairs the order was reversed. Thus there were two presentations each of the two forms of Card B. One member of each pair responded to the first card in English, the second card in French, the third card in French, and the fourth card in English. The other member performed the mirror image of this sequence, that is, he responded to the first card in French, the second in English, the third in English, the fourth in French.

Since there were two forms for each of the four kinds of Card $c$, and since each form was responded to twice, there were sixteen presentations remaining. Four random orders of the eight different forms of Card $C$ were selected, one for each of the four pairs of Ss. After responding to eight presentations, each $\underline{S}$ performed his sequence in reverse order. For instance, if the first sequence of eight presentations was $A, B, C, D, E, F, G, H$ then the second sequence was $H, G, F, E, D$, C, B, A. Each $\underline{S}$ responded to both presentations of a given form in the same language; however, the other member of his pair responded to both presentations of that same form in the other language.

Ss were tested individually at school by an undergraduate assistant. Before commencing with the first card, instructions similar to those in Appendix $B_{0} 5$ were read to each $S_{0}$ The testing procedure was similar to the other studies. As a check on reliability, Ss were retested between one and three weeks after the original testing.

\section{RESULTS AND DISCUSSION}

Since the earlier studies suggested that time scores are more sensitive indicators of interference than error scores, no error analysis 
was done in the present study. The mean time scores to complete 100 items on the ten tasks for undergraduates and graduate students on first testing are presented in Tables 33 and 34 , and for second testing in Tables 35 and 36 . The results of one-way analyses of variance for these four tables are presented in Appendices C.I and C.2. In all four cases, the $F$ value for Tasks was significant at the .01 level. Following the analyses of variance, the Newnan-Keuls procedure was applied. Significant differences are at the .05 level or better.

Color words, first testing. For both undergraduates and graduate students, the straightforward predictions $(3,4$, and 5 ) were confirmed. In Tables 33 and 34 , Cell 2 showed a significantly lower mean time score than Cells 1, 4, and 5. Predictions 7 and 8 received moderate support. The pattern of means for these predictions lay in the expected direction, that is, in both groups Cell 1 had a lower mean time score than Cells 4 and 5. In both tables, however, the Newman-Keuls test showed that only Cells 1 and 5 differed significantly. Prediction 8 suggests that Cells 4 and 5 should not differ. For both undergraduates and graduate students, there was no significant difference between these two cells although in both groups, Cell 4 had a lower mean time score than Cell 5. Finally, in both groups with the exception of Cells 2 and 6, Cells 1, 2, 4, and 5 all differed significantly from Cells 3 and 6 , indicating that even when response and interfering languages were different, the words caused interference for these "dominant" bilinguals.

Color words, second testing. The mean time scores for both groups were considerably lower on second testing (Tables 35 and 36) reflecting the effect of practice. Nevertheless, for both groups the patterns of mean time scores on second testing were identical to those found on first testing. Cell 5 showed the largest mean time score followed by 
Cells $4,1,2,6$, and 3 , in decreasing order. With one exception, the patterns of significant differences in both groups were identical to those found on first testing. In Tables 35 and 36, the mean for cell 2 was significantly lower than the means for Cells 1, 4, and 5. Cell 1 differed significantly from Cell 5 but Cells 1 and 4 were not significantly different. In Table 35, Cells 4 and 5 differed significantly but in Table 36 the means in these two cells were not significantly different. Finally, in both tables with the exception of cells 2 and 6 , Cells 1 , 2, 4, and 5 all differed significantly from Cells 3 and 6. Non-color words, first testing. In Tables 33 and 34 , the patterns of mean time scores for non-color words resembled somewhat the patterns of mean time scores for color words. Cells 1, 2, 4, and 5 correspond to Cells 7, 8, 9, and 10 for non-color words. For undergraduates and graduate students, Cell 8 had a lower mean than Cells 7 , 9, and 10, although only cells 9 and 10 differed significantly from Cell 8. Cells 9 and 10 which did not differ significantly, both had significantly larger means than cell 7. In addition, it was found that for both groups the means for naming colors of random sequences of letters in French ( $C e 11$ 6) did not differ significantly from the means for naming the colors of English or French non-color words in French (Cells 9 and 10), but cell 6 differed significantly from Cells 7 and 8 . For undergraduates, naming colors of random sequences of letters in English ( $\operatorname{Cell} 3$ ) took significantly less time than naming colors of English or French non-color words in English (Cells 7 and 8), while for graduate students there were no significant differences among these three tasks. In both groups cell 3 differed significantly from cells 9 and 10 .

Non-color words, second testing. Again the mean time scores 
for both groups were considerably lower on second testing (Tables 35 and 36). For undergraduates the pattern of significant differences was identical to the pattern found on first testing. Cells 6, 9, and 10 did not differ significantly nor did Cells 7 and 8 differ significantly. All other comparisons among Cells $3,6,7,8,9$, and 10 were significant. For graduate students the pattern of significant differences for second testing was almost identical to the pattern for first testing c Cells 6 , 9, and 10 did not differ significantly, and cells 6 and 7, Cells 7 and 8 , and Cells 3 and 8 did not differ significantly. All other comparisons among Cells $3,6,7,8,9$, and 10 were significant. Color words vs, non-color words. From Tables 33, 34, 35 and 36 , it is evident that color words cause more interference than noncolor words. In all four tables, all possible comparisons between any of Cells $1,2,4$, and 5 and any of cells $7,8,9$, and 10 were significant except for comparisons involving cell 2 with cells 9 and 10 . 
Table 33

Mean Time Scores for Undergraduate $\underline{S}$ on the Ten Tasks, First Testing

\begin{tabular}{|c|c|c|c|c|c|}
\hline & $\begin{array}{c}\text { English } \\
\text { Color words }\end{array}$ & $\begin{array}{c}\text { French } \\
\text { Color Words }\end{array}$ & $\begin{array}{c}\text { English } \\
\text { Non-color Words }\end{array}$ & $\begin{array}{c}\text { French } \\
\text { Non-color Words }\end{array}$ & Letters \\
\hline $\begin{array}{l}\text { English } \\
\text { Response }\end{array}$ & $\begin{array}{l}1 \\
\quad 93.2\end{array}$ & 88.5 & 68.6 & 8 & 60.5 \\
\hline & 4 & 5 & 9 & 10 & 6 \\
\hline $\begin{array}{l}\text { French } \\
\text { Response }\end{array}$ & 96.9 & 102.4 & 81.3 & 82.6 & 83.6 \\
\hline
\end{tabular}

Note.--There were no significant differences among Cells 2, 6, 9 and 10, between cells 1 and 4 , between Cells 4 and 5 , or between cells 7 and 8 . All other comparisons were significant, .05 level or better, Newman-Keuls test. 
Table 34

Mean Iime Scores for Graduate $\underline{S}$ s on the Ten Tasks, First Testing

\begin{tabular}{|c|c|c|c|c|c|}
\hline & $\begin{array}{c}\text { English } \\
\text { Color-Words }\end{array}$ & $\begin{array}{c}\text { French } \\
\text { Color ionds } \\
\end{array}$ & $\begin{array}{c}\text { English } \\
\text { Non-color Words }\end{array}$ & $\begin{array}{c}\text { French } \\
\text { Non-color Words }\end{array}$ & Letters \\
\hline $\begin{array}{l}\text { English } \\
\text { Response }\end{array}$ & $\begin{array}{l}1 \\
\quad 106.5\end{array}$ & $\begin{array}{l}2 \\
96.8\end{array}$ & 80.9 & 77.5 & 73.9 \\
\hline $\begin{array}{l}\text { French } \\
\text { Response }\end{array}$ & 410.9 & $\begin{array}{l}5 \\
115.2\end{array}$ & 91.2 & 89.5 & 90.0 \\
\hline
\end{tabular}

Note.--There were no significant differences among Cells 2, 6, 9 and 10, between Cells 1 and 4, between cells 4 and 5, or among Cells 3, 7 and 8 . All other comparisons were significant, .05 level or better, Newman-Keuls test. 
Table 35

Mean Time Scores for Undergraduate $\underline{S}$ s on the Ten Tasks, Second Testing

\begin{tabular}{|c|c|c|c|c|c|}
\hline & $\begin{array}{c}\text { English } \\
\text { Color Words }\end{array}$ & $\begin{array}{c}\text { French } \\
\text { Color Words }\end{array}$ & $\begin{array}{l}\text { English } \\
\text { Nion-color Wonds }\end{array}$ & $\begin{array}{l}\text { French } \\
\text { Non-color Words }\end{array}$ & Letters \\
\hline $\begin{array}{l}\text { English } \\
\text { Response }\end{array}$ & $\begin{array}{l}1 \\
81.1\end{array}$ & $\begin{array}{l}2 \\
70.4\end{array}$ & 7 & 8 & 52.3 \\
\hline & 4 & 5 & 9 & 10 & 6 \\
\hline $\begin{array}{l}\text { French } \\
\text { Response }\end{array}$ & 83.2 & 89.4 & 74.5 & 74.2 & 68.9 \\
\hline
\end{tabular}

Note.--There were no significant differences among Cells 2, 6, 9 and 10, between Celis 1 and 4, or between Cells 7 and 8. All other comparisons were significant, .05 level or better, Newman-Keuls test. 
Mean Time Scores for Graduate $\underline{S}$ s on the Ten Tasks, Second Testing

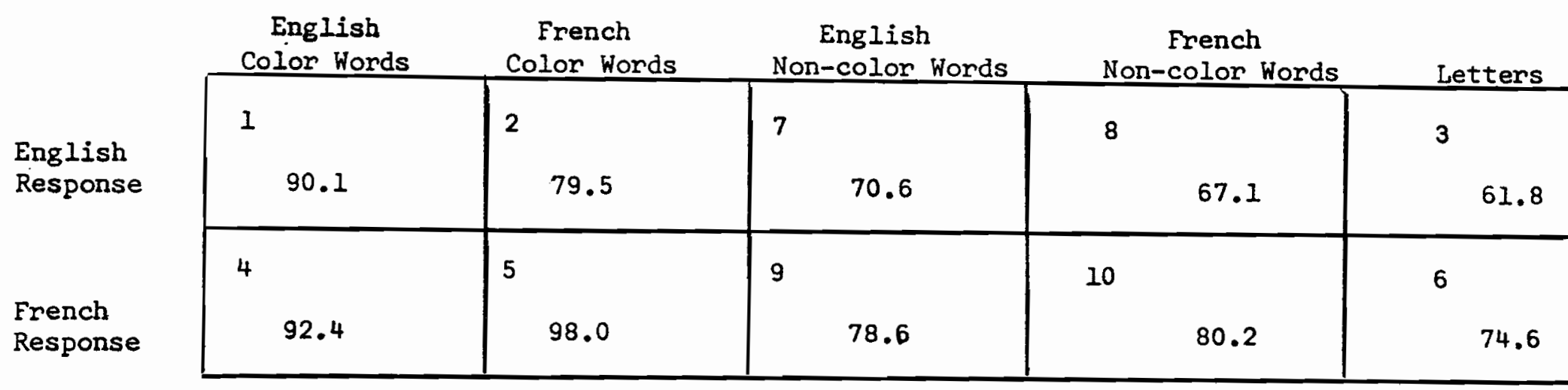

Note.--There were no significant differences anong Cells 2, 6, 9 and 10, between Cells 1 and 4, between Cells 4 and 5, between Cells 6 and 7, between Cells 7 and 8 or between Cells 3 and 8 . All other comparisons were significant .05 level or better, Newnan-Keuls test. 
CHAPTER VI

OVERVIEW AND DISCUSSION

The model proposed in Chapter II suggests that two sets of processes (subsystems) are activated in the color-word task, one for word reading and one for color naming. It is presumed that the word reading subsystem consists of (1) a perceptual process for decoding the word (input process for words), (2) an already established internal representation of the word (word-unit), and (3) a motor process for the oral production of the word, when the task calls for reading the word aloud. The color naming subsystem consists of (1) a perceptual process for decoding the color of the word (input process for color), (2) an internal unit corresponding to the color (color-unit), (3) a process which selects the proper label or name for the color (word search process), (4) an internal representation of the labelling word (word-unit), and (5) a motor process for the production of the spoken word, when required by the task. It is assumed that practice is a factor affecting how efficiently these processes function. Further, it is assumed that the word reading subsystem, particularly the input process for words, is so highly practiced 
that it functions automatically when the stimulus is a word and thus causes interference with color naming in the color-word task. A selective process is postulated which attempts to "gate out" the word reading subsystem, thus reducing interference in color naming. It is assumed that the more similar are the two kinds of information processed by the two subsystems, the less efficient the selective process will be in "gating out" the word reading subsystem.

Study 1 examined some predictions following from assumptions made about the input process for words and the selective process. First, since it is assumed that the efficiency of the input process for words increases with practice, it is likely that high frequency words will enter the word reading subsystem more easily than low frequency words o Thus, high frequency words as the color bearing stimuli should cause more interference than low frequency words. Second, since it is assumed that the selective process will "gate out" the interfering word reading subsystem more easily when the two subsystems are processing different kinds of information, it follows that non-color words will cause less interference than color words.

Two main findings were obtained from Study 1. First, low frequency non-color words show only a slight tendency to cause less interference than high frequency non-color words. The mean time to complete low frequency non-color word cards was $14 \%$ less than the mean time to complete high frequency non-color word cards. In addition, only a few more errors were made on the high frequency non-color word cards than on the low. These results are consistent with Rouse $\varepsilon$ Mass (1961) who found that practice on nonsense syllables increased slightly their likelihood of causing interference in the color-word task. The relatively mild effect of frequency noted above suggests that sufficient over-learning 
had taken place with low frequency words so that they were decoded nearly as efficiently as the high frequency words. On the other hand, Ss may have "paid more attention" to the low frequency words thus increasing the amount of time to complete the task and decreasing the difference between the means for high and low frequency words.

The second main finding of Study 1 is that there is a strong tendency for color words to cause more interference than non-color words of the same frequency. The mean time for completion of the non-color word cards was about $28 \%$ less than the mean time for completion of the color word cards. In addition, considerably more errors were made on the color word cards in contrast to the non-color word cards. These results agree with Klein (1964) who also found that non-color words caused less interference than color words.

Studies 2 and 3 , also concerned with the selective process, examined inter-lingual interference in a bilingual version of the colorword task. Following from the assumption made about the efficiency of the selective process, it was predicted that if the input process for words, the word search process, and the motor process all functioned equally well in both languages, then bilingual Ss would suffer less interference when the response language and the language of the color bearing stimuli were different than when the response and interfering languages were the same. The Ss selected for studies 2 and 3 were fluent in both of their languages.

The results of these two studies show that, for these "balanced" bi.linguals, there is a slight tendency for less interference (about 10\%) to occur when response and interfering languages are different than when they are the same but only if the translated equivalents of the color words employed have different stimulus characteristics (e.go, black - 
schwarz ).

In terms of the proposed model, there are at least two ways of accounting for these findings. First, a word may evoke the word-unit normally evoked by its translation, if the two words have similar stimulus characteristics. As an example, for an English-German bilingual, the printed word BROWN may evoke not only the word-unit corresponding to brown but also, presumably to a lesser extent, the word-unit corresponding to braun. Under these conditions, $\underline{S}$ asked to respond in German may suffer as much interference when the printed words are in English as they do when the printed words are in German. Second, a word-unit in one language may evoke, through a translation process, the word-unit corresponding to its translation, irrespective of the similarities between the corresponding printed words. For instance, the word-unit for the printed word BLACK may evoke, through the hypothetical translation process, the word-unit for schwarz, again making it likely that printed English words will cause almost as much interference as printed German words when color naming is done in German. The second explanation is supported by the fact that next to non-linguistic utterances, the most common error given by "balanced" bilinguals, when response and interfering languages were different and when the color words employed did not have translations with similar stimulus characteristics, was the translation of the printed color word. The latter explanation may also account for the finding that the interference suffered from non-color words was considerably less than that suffered by bilingual Ss from color words when response and interfering languages were different, since non-color words are less likely to evoke a competing word-unit corresponding to a color.

In Study 4 a set of predictions for "dominant" bilinguals was examined. Since these bilinguals were native speakers of English studying 
French as a major subject and since they took longer to name the colors of blocks of letters in French than in English, it was assumed that the input process for words, the word search process, and the motor process all functioned more efficiently in English than in French. A set of predictions for color words was generated for the six possible comparisons between Cells 1, 2, 4, and 5 in Table 1. In all comparisons there were at least two factors to take into consideration. In three of these comparisons (Cell 2 vs. Cells 1,4 , and 5), the relevant factors worked in the same direction, and the predictions were straightforward. In the other three comparisons, the relevant factors worked in opposition and the predictions depended on the weights of the relevant factors. Rough estimates of these weights were obtained from the results of the earlier studies and from performance in the two languages on the cards with blocks of letters. These estimates suggested that the word search process and the motor process should be assigned heavier weights than the input process for words or the selective process. Using these rough estimates, a tentative set of predictions was made for the last three comparisons. The predictions, both straightforward and tentative, suggested that Cell 2 should have a lower time score than cells 1,4 and 5 , that cell 1 should have a lower time score than Cells 4 and 5 , and that Cells 4 and 5 should have approximately equal time scores. In addition, $\underline{S}$ s in Study 4 also responded to a set of non-color word cards to determine whether the same pattern of time scores for color words would also be obtained for noncolor words. Finally, as a check on reliability, Ss were retested one to three weeks after the original testing。

The three predictions for color words in which the relevant factors all worked in the same direction were confirmed (Cell 2 vs. Cells 1, 4 and 5), that is, the easiest task was that in which the interfering 
color words were in the non-dominant language while color naming was done in the dominant language. When response and interfering languages were both in the dominant language, the task was easier than when response and interfering languages were both in the non-dominant language (Cell 1 vs. Cell 5). When response and interfering languages were both in the dominant language, the task was easier although not significantly easier than when color naming was done in the non-dominant language and the interfering words were in the dominant language (Cell I vs. Cell 4)。 Finally, when color naming was done in the non-dominant language, there was no significant difference between interference caused by printed words in the dominant language and the non-dominant language (Cell 4 vs. Cell 5)。 Thus, two of the three tentative predictions were confirmed and the means for the unconfirmed prediction fell in the expected direction.

The pattern of mean time scores for non-color words was generally the same as that shown for color words, that is, the easiest task was that in which the interfering words were in the non-dominant language and the response was in the dominant language. The second most easy task was that in which both response and interfering languages were dominant and the two most difficult tasks were those in which color naming was done in the non-dominant language. Had the predictions for color words been extended to non-color words, all would have been confirmed with the exception of the comparison between the first and second most easy tasks which did not reach significance although for both groups on both testings, the means were always in the expected direction (Cell 8 vs. Cell 7 in Tables $33,34,35$ and 36 ).

The mean time scores for color words were all significantly higher than the mean time scores for non-color words with the exception of the comparisons between the task in which color naming was done in the dominant 
language and the interfering words were the names of colors in the nondominant language with the two tasks in which color naming was done in the non-dominant language and the interfering words were non-color words in either the dominant or non-dominant language (Cell 2 vs. Cells 9 and 10 in Tables $33,34,35$ and 36 ). Taking into the account that these "dominant" bilinguals took about $30 \%$ more time to name the colors of blocks of letters in French than in English, these findings are consistent with Studies 1, 2, and 3 where it was found that color word - non-color word variation produced a greater effect than either high frequency low frequency variation or language variation of color words with balanced bilinguals ( $28 \%, 14 \%$ and $10 \%$ respectively). Thus in comparing time scores for color words with those for non-color words, significant differences would least likely occur in comparisons between tasks in which the two heavily weighted factors work in opposition (color word vs. non-color word and naming colors in the dominant vs. non-dominant language). This occurs only in comparisons between tasks in which color naming occurs in the dominant language and the interfering words are color words and tasks in which color naming occurs in the non-dominant language and the interfering words are non-color words.

The pattern of results for second testing was very similar to that for first testing with the exception that the mean time scores were lower on second testing indicating the effect of practice. Spearman's coefficient of rank correlation between the mean time scores of first and second testing was .95 for undergraduates and .93 for graduate students, both significant at the .01 level. Thus in spite of the practice effect, these findings are highly reliable.

The results of these four studies clearly suggest that in com- 
parisons between any two color-word tasks which differ in some respect, a number of factors of different weights may be operating. In some comparisons, these factors may work in the same direction and in others they may work in opposition, the net result depending on their relative weights. The weights to be assigned to three of these factors, the ability to decode words, the ability to label a color quickly and facility in oral production of the words, may vary depending upon the degree of "dominance" or "balance" of the bilinguals. Thus, as a "dominant" bilingual becomes "balanced" through greater experience in his non-dominant language, the weights of these factors should change yielding a different pattern of results. Further experiments involving a greater difference along the "dominance - balance" dimension than that employed in Study 4 are needed to explore this change.

With respect to the problem of bilingualism per se, the most interesting finding of these studies is that bilinguals suffer interlingual interference in the color-word task. This is shown in Studies 2 and 3 by the highly significant differences in comparisons between the Card $B$ tasks and the tasks in which response and interfering languages were different. This effect can also be noted for "dominant" bilinguals in study L. It seems, then, at least as far as the color-word task is concerned, there is little support for the notion of a switch mechanism which effectively shuts off processes functioning in one language system while the other language system is in operation. Rather, it appears that while color naming is occurring in one language, processes involved in decoding words in another language as well as processes involved in translating the word into the first language may occur with consequent interference in color naming. All of this apparently happens in spite 
of the best efforts of the $\underline{S}$.

Further experiments are needed to explore the nature of this translation process. For instance, bilinguals who work as translators may be more likely to suffer inter-lingual interference than bilinguals who habitually use their two languages in separate environments even though both kinds of bilingual are balanced with respect to the ability to decode words and the ability to label and produce orally the name of a color quickly. In a similar manner, compound bilinguals should suffer more inter-lingual interference than coordinate bilinguals since compounds presumably have one meaning response for translated equivalents in their two languages thus facilitating the translation process. These experiments could be carried out using non-color words as the color bearing stimuli.

In general, then, experiments utilizing variations in the colorword task may cast light not only on the phenomenon of word interference in color naming as such, but also on the manner in which bilingual language systems are inter-related. 
SUMMARY

The aim of the present experiments was to determine to what extent and under what conditions inter-lingual interference occurs in bilinguals, making use of a bilingual version of the Stroop color-word task. In the original version of this task, a card containing several rows of words is presented to $\underline{S}$. Each word is printed in one of four different colors. The words themselves are the names of colors and no word ever appears in the color it names. For instance, the word RED might be printed in blue, green or brown ink, but never in red. $\underline{S}^{\prime}$ s task is to name the color of the inks as fast and as accurately as possible. Invariably, Ss take more time and usually make more errors when naming the colors of color-words than when naming the colors of an equivalent series of patches, indicating that the printed words interfere in some fashion with color naming。

In the bilingual version, two word cards are employed, each containing color words from one language only. Bilingual Ss name the colors of the words on both cards at some point in the experiment in both languages. For instance, if the two languages were English and French, Ss would name (1) the English card in English, (2) the English card in French, (3) the French card in English and (4) the French card in French. As a control, Ss would also name the colors of patches on a third card in both languages. Interest in the present experiments centers on contrasting the performance of $S s$ in those situations where response and interfering languages are different ( $e_{\circ} g \circ g$ naming the English card in French or the French card in English) with the situations in which response and interfering languages are the same ( $e_{\circ} g$, naming the English card in English 
or the French card in French)。

A model of the processes involved in the color-word task was used to make a set of predictions for both "balanced" and "dominant" bilinguals. The model suggests that a "balanced" bilingual should be able to decode printed words, find the names of colors and produce them orally equally well in both languages. On the other hand, "dominant" bilinguals should be more proficient in all three of these skills in one of their two languages. The model predicted that low frequency words should cause less interference than high frequency words, that non-color words should cause less interference than color words, and that with "balanced" bilinguals, less interference should occur when response and interfering languages were different than when they were the same. For "dominant" bilinguals, the model predicted that the easiest task should be the one in which color naming was done in the dominant language while the interfering words were in the non-dominant language. The second easiest task should be the one in which response and interfering languages were in the dominant language. The two most difficult tasks which should not differ from each other should be those in which color naming was done in the non-dominant language and interfering words were in either the dominant or non-dominant language.

Study 1 , in which 40 monolinguals served as Ss, showed that low Erequency non-color words caused slightly less interference (14\%) than high frequency non - color words, while non-color words caused considerably less interference ( $28 \%$ ) than color words matched with them on frequency. Studies 2 and 3 , employing 32 "balanced" bilinguals as Ss, showed that there was a slight tendency for less interference (about $10 \%$ ) to occur when response and interfering languages were different than when 
they were the same but only if the translated equivalents of the color words employed had different stimulus characteristics ( $e_{\circ} g$. black - schwarz)。 If the translated equivalents had similar stimulus characteristics (e.g。, brown - braun), inter-lingual interference did not differ from intralingual interference. Study 4, employing 16 "dominant" bilinguals, generally confirmed the predictions for this type of bilingual. In addition, the results of Study 4 indicated that the predictions also held for noncolor words, although the non-color words caused less interference as a whole than the color words.

The results of the last three studies provide little support for the notion that there is a switch mechanism which shuts off processes functioning in one language system while the other language system is in operation. Instead, it appears that while color naming is occurring in one language, processes involved in decoding words in another language as well as a process involved in translating the words into the first language may occur thus producing interference in color naming. Further research might profit by exploring the nature of this translation process For instance, compound bilinguals should suffer more inter-lingual interference than coordinate bilinguals since compound bilinguals pre= sumably have one meaning response for translated equivalents in their two languages thus facilitating the translation process. 


\section{REFERENCES}

Brown, W. Practice in associating color-names with colors. Psychol. Rev., $1915,22,45-55$ 。

Chase, $R_{0} A$. An information-flow model of the organization of motor activity。 Publication of the $U_{0} S_{0}$ Department of Health, Education and Welfare, Public Health Service, Aug。1963。

Chomsky, No Syntactic structures. The Hague: Mouton $\&$ Co., 1957. Ervin, Susan $M_{0}, \varepsilon$ Osgood, $C_{0} E_{0}$ Second language learning and bilingualism。 J. abnorm。soc. Psychol. Suppl., 1954, 49, 139-146。

Grand, S。 $E$ Segal, SoJ。 Recovery in the absence of recall: an investigation of color-word interference. J。exp.Psychol., 1965, in press.

Hebb, D.O. A textbook of psychology. Philadelphia: W.B. Saunders CO., 1958.

Istomina, Z.M. Perception and naming of color in early childhood。 Soviet Psychol。Psychiat. $1963, \underline{1}, 37-45$ 。

Jakobovits, L。A。 $\varepsilon$ Lambert, $W_{\circ} E_{0}$ Semantic satiation among bilinguals。 Joexp。Psychol $。 1961,62,576=582$ 。

Klein, G.S. Semantic power measured through the interference of words with color naming, Amer. Jo Psycholo $1964,17,576-588$ 。

Kolers, $P$. Interlingual word associations. Joverb, Learn。 verb. Behav。o $1963,2,291-300$.

Lambert, $W_{0} E$ 。 Behavioral evidence for contrasting forms of bilingualism。 Paper read at George University Symposium, Washington, D。C。, 1962.

Lambert, $W_{0} E_{0}$, E Fillenbaum, S, A pilot study of aphasia among bilinguals。 Canad。 U. Psychol, 1959, I3, 28-34。 
REFERENCES (Cont'd)

Lambert, W.E., Havelka, J., $\varepsilon$ Crosby, C. The influence of language acquisition contexts on bilingualism. J。abnorm. soc. Psychol., $1958,56,239-244$ 。

Lenneberg, $E_{0}$ The biological bases of language. Unpublished manuscript, Harvard, 1964 .

Liberman, A.M., Cooper, F。S., Harris, Katherine S。, E MacNeilage, P॰F。 A motor theory of speech perception. Paper read at the Speech Communication Seminar, Royal Institute of Technology, Stockholm, Sept. 1962.

Liberman, A.M., Cooper, F。S., Harris, Katherine S。, MacNeilage, P॰F。, E Studdert-Kennedy, Mo Some observations on a model for speech perception. Paper read at AFCRL Symposium on Models for the Perception of Speech and Visual Form, Boston, Nov。 1964.

Masland, D.H. Attention in the Stroop color word test. Unpublished undergraduate thesis, Harvard University, 1964.

Morton, $J_{0}, E$ Broadbent, $D_{0} E$. Passive vs active recognition models or is your homunculus really necessary? Paper read at AFCRL Symposium on Models for the Perception of Speech and Visual Form, Boston, Nov。1964。

Neisser, U. Experiments in visual search and their theoretical implications. Paper read at Psychonomic Society, Niagara Falls, Ont., Oct. 1964. Olton, RoM。 Semantic generalization between languages. Unpublished master's thesis, McGill University, 1960 .

Osgood, C.E. Method and theory in experimental psychology New York: Oxford University Press, 1953. 


\section{REFERENCES (Cont'd)}

Osgood, C.E. On understanding and creating sentences. Amer. Psychologist, $1963,18,735-751$ 。

Penfield, W., E Roberts, L。 Speech and brain mechanisms. Princeton: Princeton University Press, 1959.

Postman, Lo, \& Conger, Beverly. Verbal habits and the visual recognition of words. Science, 1954, 119, 671-673.

Rand, G., Wapner, S., Werner, H., E McFarland, J.H. Age differences in performance on the stroop color-word test. J.Pers., 1963, $31,534-558$.

Rosenzweig, M.R。, $\varepsilon$ Postman, L。 Frequency of usage and the perception of words. Science, 1958, 127, 263-266。

Rouse, $R_{0} O_{0}, E$ Maas, J.B. Interference with color naming as a function of degree of practice on the color-bearing materials. Paper read at Eastern Psychol. Ass., Philadelphia, 1961。

Selfridge, $O_{0} G_{0}, E$ Neisser, $U_{0}$ Pattern recognition by machine, Sci。Amer., $1960,203,60-68$.

Stroop, JoR, Studies of interference in serial verbal reactions。 $J_{0}$ exp。 Psycholo, 1935a, 18, 643-661.

Stroop, J.R. The basis of Ligon's theory. Amer. J.Psychol. 1935b, 47, 499-504.

Stroop, JoR。 Factors affecting speed in serial verbal reactions. Psychol. Mono., $1938,50,38-48$.

Thorndike, E。L., E Lorge, I。 The teacher's word book of 30,000 words: New York: Columbia University Press, 1944 。 


\section{REFERENCES (Cont'd)}

Uhr, L. Pattern recognition computers as models for form perception. Psychol. Bull., 1963, 60, 40-73.

Uhr, L., $\varepsilon$ Vossler, C. A pattern recognition program that generates, evaluates and adjusts its own operators. Proc. West.Joint Comput. Conf., 1961, 19, 555-569.

Weinreich, U. Languages in contact. New York: Linguistic Circle of New York, 1953。

Winer, B.J. Statistical principles in experimental design. New York: McGraw-Hill, 1962. 
APPENDICES 


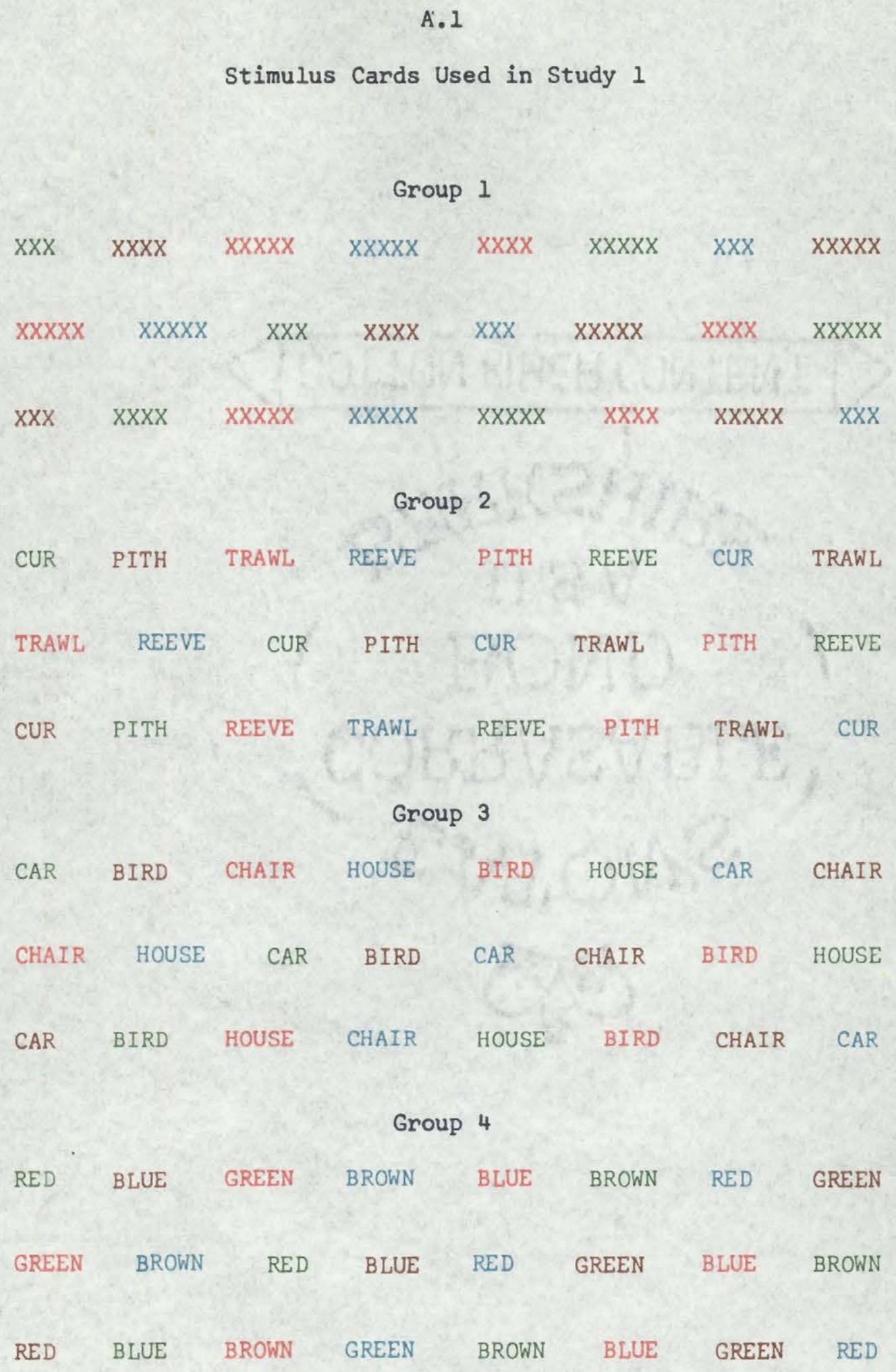




$$
\text { A. } 2
$$

Analyses of Variance for Study 1

\begin{tabular}{lcccr} 
Source & df & Mean Square & $F$ & $\mathrm{p}$ \\
\hline Groups & 3 & 184.78 & 42.77 & .01 \\
Separate-together & 1 & 55.93 & 12.95 & .01 \\
Interaction & 3 & 7.14 & 1.65 & $\mathrm{~ns}$ \\
Within & 32 & 4.32 & & \\
\hline
\end{tabular}


B. 1

English Card $C$ in Study 2

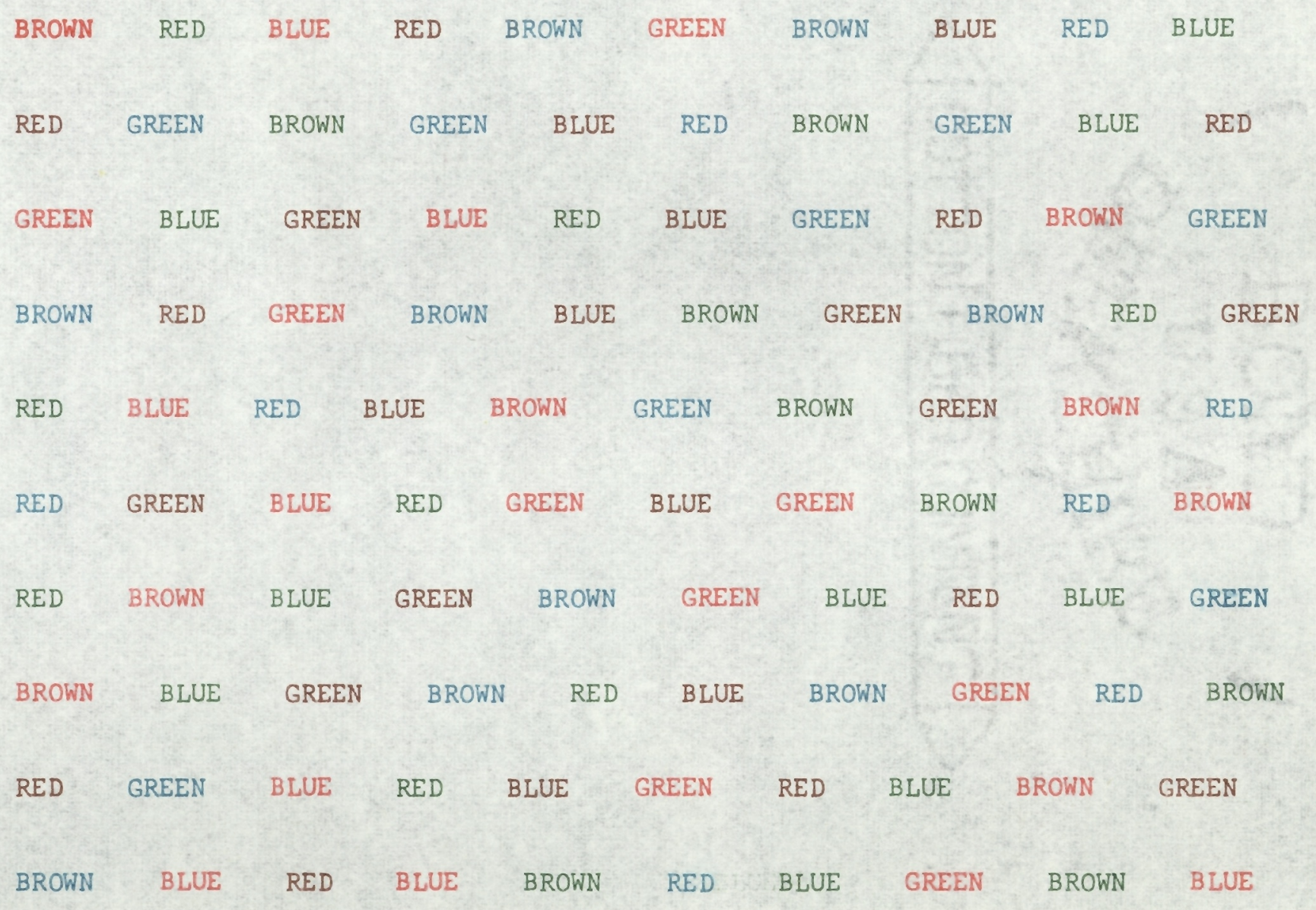




\section{B. 2}

French Card C in Study 2

$\begin{array}{llllllllllll}\text { BRUN } & \text { ROUGE } & \text { BLEU } & \text { ROUGE } & \text { BRUN } & \text { VERT } & \text { BRUN } & \text { BLEU } & \text { ROUGE } & \text { BLEU } \\ \text { ROUGE } & \text { VERT } & \text { BRUN } & \text { VERT } & \text { BLEU } & \text { ROUGE } & \text { BRUN } & \text { VERT } & \text { BLEU } & \text { ROUGE } \\ \text { VERT } & \text { BLEU } & \text { VERT } & \text { BLEU } & \text { ROUGE } & \text { BLEU } & \text { VERT } & \text { ROUGE } & \text { BRUN } & \text { VERT } \\ \text { BRUN } & \text { ROUGE } & \text { VERT } & \text { BRUN } & \text { BLEU } & \text { BRUN } & \text { VERT } & \text { BRUN } & \text { ROUGE } & \text { VERT } \\ \text { ROUGE } & \text { BLEU } & \text { ROUGE } & \text { BLEU } & \text { BRUN } & \text { VERT } & \text { BRUN } & \text { VERT } & \text { BRUN } & \text { ROUGE } \\ \text { ROUGE } & \text { VERT } & \text { BLEU } & \text { ROUGE } & \text { VERT } & \text { BLEU } & \text { VERT } & \text { BRUN } & \text { ROUGE } & \text { BRUN } \\ \text { ROUGE } & \text { BRUN } & \text { BLEU } & \text { VERT } & \text { BRUN } & \text { VERT } & \text { BLEU } & \text { ROUGE } & \text { BLEU } & \text { VERT } \\ \text { BRUN } & \text { BLEU } & \text { VERT } & \text { BRUN } & \text { ROUGE } & \text { BLEU } & \text { BRUN } & \text { VERT } & \text { ROUGE } & \text { BRUN } \\ \text { ROUGE } & \text { VERT } & \text { BLEU } & \text { ROUGE } & \text { BLEU } & \text { VERT } & \text { ROUGE } & \text { BLEU } & \text { BRUN } & \text { VERT } \\ \text { BRUN } & \text { BLEU } & \text { ROUGE } & \text { BLEU } & \text { BRUN } & \text { ROUGE } & \text { BLEU } & \text { VERT } & \text { BRUN } & \text { BLEU }\end{array}$


B. 3

Hungarian Card $C$ in Study 2

\begin{tabular}{|c|c|c|c|c|c|c|c|c|c|}
\hline BARNA & PIROS & KEK & PIROS & BARNA & ZOLD & BARN & KEK & PIROS & KEK \\
\hline PIROS & Z̈LLD & BARNA & ZÖLD & KÉK & PIROS & BARNA & ZÖLI & KÉK & PIROS \\
\hline ÓLD & KEK & Z̈̈LD & KEK & ROS & KÉK & Z̈LLD & IROS & BARNA & ZOLDD \\
\hline BARNA & PIROS & ZÖLD & BARN & KÉK & BARNA & ZÖLD & BARN & PIRO & ZOLD \\
\hline PIROS & KEK & PIROS & KEK & BARNA & ZOLD & BARNA & ZOLD & BARNA & PIROS \\
\hline IROS & ZÖLD & KE'K & PIROS & ZÖLD & KÉKK & ZÖLD & BARNA & PIROS & BARNA \\
\hline PIROS & BARNA & KÉK & ZOLD & BARNA & ZOLD & KÉK & PIROS & KÉK & ZOLLD \\
\hline BARNA & KÉK & ZÖLD & BARNA & PIROS & KÉK & BARNA & ZOLDD & PIROS & BARNA \\
\hline IROS & ZÖLD & KÉK & PIROS & KÉK & ZÖLD & PIROS & KÉK & BARNA & ZÖLD \\
\hline NA & KÉK & PIROS & KÉK & BARNA & PIROS & KÉK & ZÖLD & BARNA & KÉK \\
\hline
\end{tabular}


English Card B in Study 2

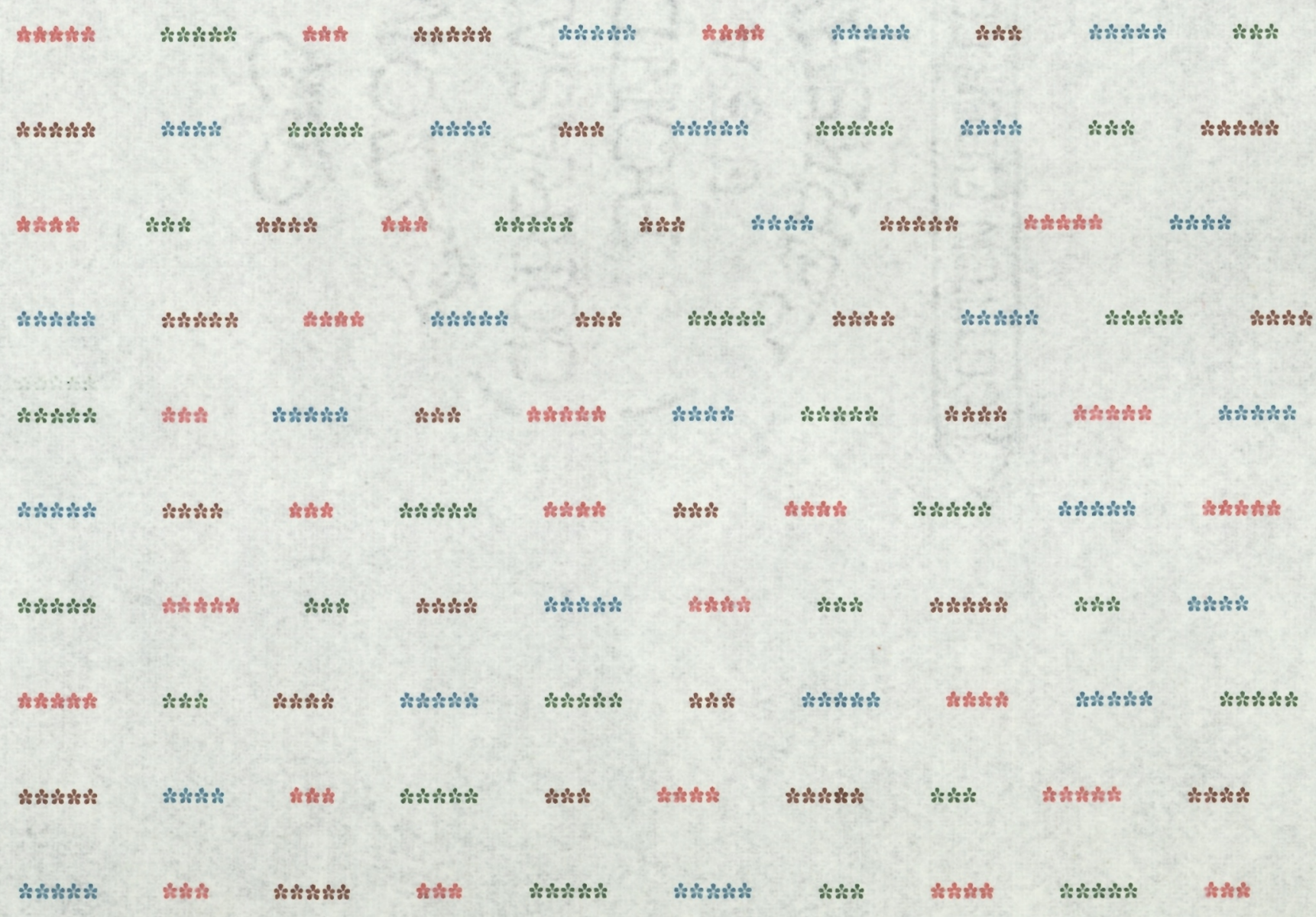




\section{B. 5}

\section{Instructions for Study 2}

The purpose of this project is to see how fast one can name various arrays of colors; and, since you are bilingual, we would like to see how fast you can name colors in both languages.

I am going to present a sheet of paper containing groups of colored asterisks, and I want you to name the color of each group of asterisks as fast as you can in without making a mistake.

If you make a mistake, correct it. When naming the colors, do not squint your eyes, look out of the corner of your eyes, or point your finger at the group of asterisks. Are there any questions?

$$
\begin{aligned}
& \text { (Before each stimulus card was presented, } S \\
& \text { was told which language to use. After the } \\
& \text { asterisk cards were completed the following } \\
& \text { new instructions were given.) }
\end{aligned}
$$

I am now going to present a sheet of paper containing words printed in different colors. I want you to name the COLOR OF THE WORD。 DO NOT READ THE WORD. The words will be the names of colors but no word will appear in its color. I repeat: do not read the word. Name the color of the words as fast as you can in without making a mistake. If you make a mistake, correct it. Remember: do not squint your eyes, look out of the corner of your eyes, or point your finger at the words. Are there any questions?

(Before each stimulus card was presented, $\underline{S}$ was told which language to use.) 
B. 6

Analyses of Variance on Time Scores for E-H and E-F Ss in Study 2

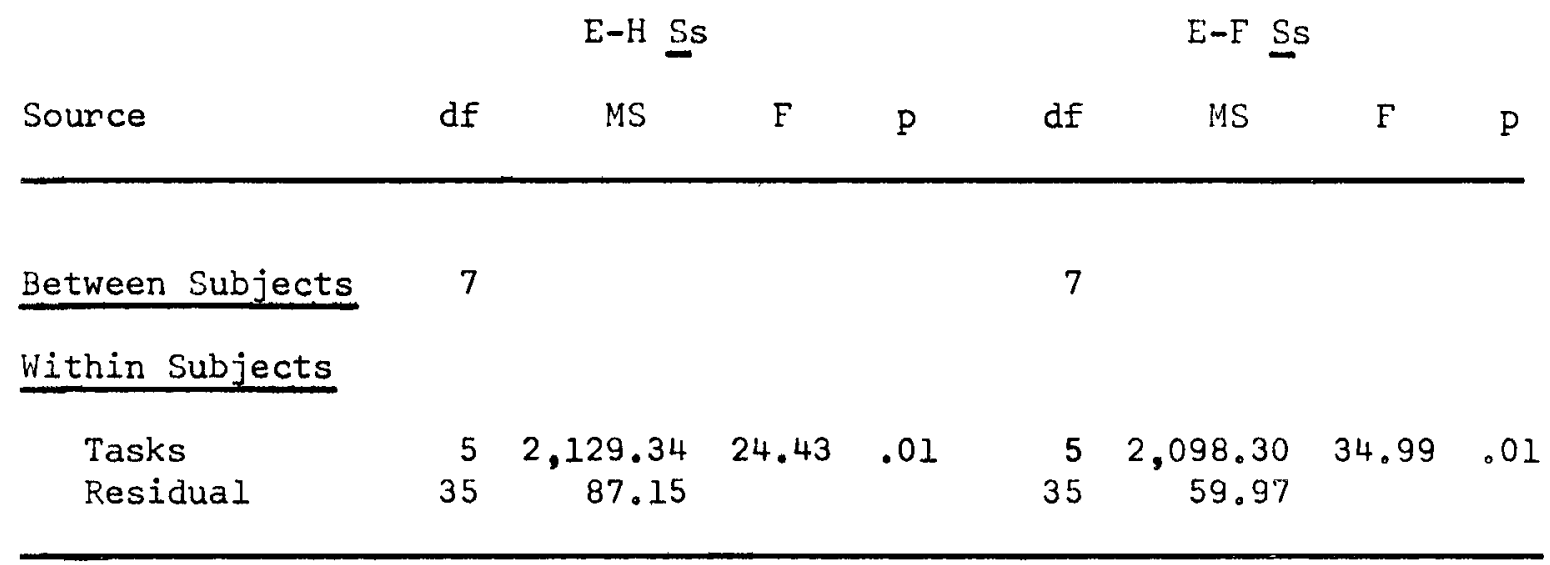




$$
\text { B. } 7
$$

Analyses of Variance on Total Errors for E-H and E-F Ss in Study 2

\begin{tabular}{|c|c|c|c|c|c|c|c|c|}
\hline \multirow[b]{2}{*}{ Source } & \multicolumn{3}{|c|}{$E-H S s$} & \multicolumn{5}{|c|}{$E-F S s$} \\
\hline & $d f$ & MS & $\mathrm{F}$ & $\mathrm{p}$ & $\mathrm{df}$ & MS & F & $\mathrm{p}$ \\
\hline Between Subjects & 7 & & & & 7 & & & \\
\hline Within Subjects & & & & & & & & \\
\hline Tasks & 5 & 66.04 & 2.86 & .05 & 5 & 110.15 & 3.49 & .05 \\
\hline Residual & 35 & 23.10 & & & 35 & 31.53 & & \\
\hline
\end{tabular}


B. 8

Analyses of Variance on Linguistic Errors for E-H and E-F

Ss in Study 2

\begin{tabular}{|c|c|c|c|c|c|c|c|c|}
\hline \multirow[b]{2}{*}{ Source } & \multicolumn{3}{|c|}{$E-H S s$} & \multicolumn{5}{|c|}{$E-F S s$} \\
\hline & $d f$ & MS & $\mathrm{F}$ & $\mathrm{p}$ & $\mathrm{df}$ & MS & F & $\mathrm{p}$ \\
\hline Between Subjects & 7 & & & & 7 & & & \\
\hline Within Subjects & & & & & & & & \\
\hline Tasks & 5 & 1.88 & 0.42 & ns & 5 & 22.87 & 5.34 & .01 \\
\hline Residual & 35 & 4.45 & & & 35 & 4.28 & & \\
\hline
\end{tabular}




$$
\text { B. } 9
$$

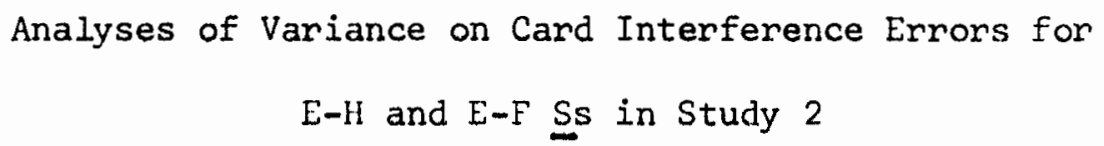

\begin{tabular}{|c|c|c|c|c|c|c|c|c|}
\hline \multirow[b]{2}{*}{ Source } & \multicolumn{4}{|c|}{$E-H S s$} & \multicolumn{4}{|c|}{$E-F \underline{S} s$} \\
\hline & $d f$ & MS & $F$ & $\mathrm{p}$ & $\mathrm{df}$ & MS & F & $p$ \\
\hline Between Subjects & 7 & & & & 7 & & & \\
\hline Tasks & 3 & 1.67 & .60 & ns & 3 & 9.03 & 2.85 & ns \\
\hline Residual & 21 & 2.79 & & & 21 & 3.17 & & \\
\hline
\end{tabular}


B. 10

Analyses of Variance on Time Scores for Groups 1 and 2 in Study 3

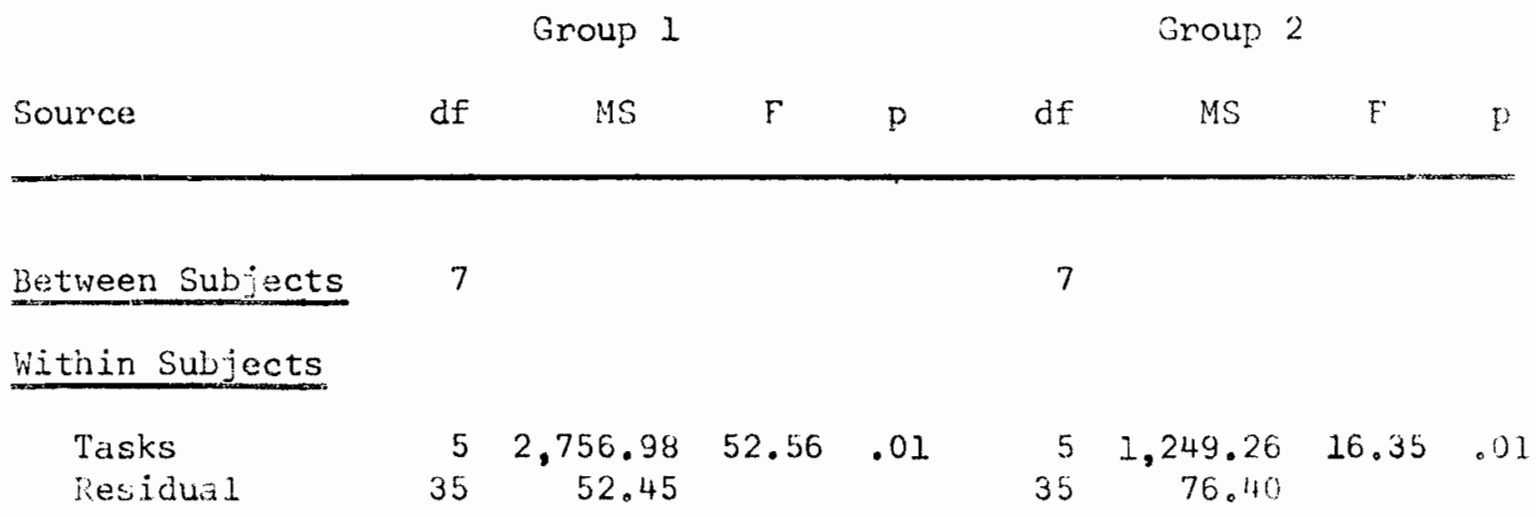


B. 11

Analyses of Variance on Total Errors for Groups 1 and 2 in Study 3

\begin{tabular}{|c|c|c|c|c|c|c|c|c|}
\hline \multirow[b]{2}{*}{ Source } & \multicolumn{4}{|c|}{ Group 1} & \multicolumn{4}{|c|}{ Group 2} \\
\hline & $d f$ & MS & $F$ & $\mathrm{p}$ & $d f$ & MS & $\mathrm{F}$ & $\mathrm{p}$ \\
\hline Between Subjects & 7 & & & & 7 & & & \\
\hline Tasks & 5 & 40.08 & 2.67 & .05 & 5 & 49.67 & 2.95 & .05 \\
\hline Residual & 35 & 15.03 & & & 35 & 16.85 & & \\
\hline
\end{tabular}




$$
\text { B. } 12
$$

Analyses of Variance on Linguistic Errors for Groups 1 and 2 in Study 3

\begin{tabular}{|c|c|c|c|c|c|c|c|c|}
\hline \multirow[b]{2}{*}{ Source } & \multicolumn{4}{|c|}{ Group 1} & \multicolumn{4}{|c|}{ Group 2} \\
\hline & $d f$ & MS & $F$ & $\mathrm{p}$ & $d f$ & MS & $\mathrm{F}$ & $\mathrm{p}$ \\
\hline Between Subjects & 7 & & & & 7 & & & \\
\hline Within Subjects & & & & & & & & \\
\hline Tasks & 5 & 8.77 & 1.96 & ns & 5 & 8.02 & 1.64 & ns \\
\hline Residual & 35 & 4.48 & & & 35 & 4.88 & & \\
\hline
\end{tabular}


B. 13

Analyses of Variance on Card Interference Errors for

Groups 1 and 2 in Study 3

\begin{tabular}{|c|c|c|c|c|c|c|c|c|}
\hline \multirow[b]{2}{*}{ Source } & \multicolumn{4}{|c|}{ Group 1} & \multicolumn{4}{|c|}{ Group 2} \\
\hline & $d f$ & MS & F & $\mathrm{p}$ & $\mathrm{df}$ & MS & F & $\mathrm{p}$ \\
\hline Between Subjects & 7 & & & & 7 & & & \\
\hline Within Subjects & & & & & & & & \\
\hline $\begin{array}{l}\text { Tasks } \\
\text { Residual }\end{array}$ & $\begin{array}{r}3 \\
21\end{array}$ & $\begin{array}{l}4.78 \\
1.90\end{array}$ & 2.52 & ns & $\begin{array}{r}3 \\
21\end{array}$ & $\begin{array}{l}2.87 \\
3.16\end{array}$ & .91 & ns \\
\hline
\end{tabular}




$$
\text { C.I }
$$

\section{Analyses of Variance on Time Scores for Undergraduate Ss in Study 4, First and Second Testings}

\begin{tabular}{llllllllllll} 
& \multicolumn{3}{c}{ First Testing } & \multicolumn{3}{c}{ Second Testing } \\
Source & df & MS & F & p & df & MS & $F$ & P \\
\hline
\end{tabular}

Between Subjects

7

7

Within Subjects

\begin{tabular}{|c|c|c|c|c|c|c|c|c|}
\hline Tasks & 9 & 1451.83 & 34.55 & .01 & 9 & 1036.40 & 33.63 & .01 \\
\hline Residual & 63 & 42.02 & & & 63 & 30.82 & & \\
\hline
\end{tabular}




$$
\text { C. } 2
$$

\section{Aralyses of Variance on Time Scores for Graduate $\underline{S}$ in Study 4, First and Second Testing}

\begin{tabular}{|c|c|c|c|c|c|c|c|c|}
\hline \multirow[b]{2}{*}{ Source } & \multicolumn{4}{|c|}{ First Testing } & \multicolumn{4}{|c|}{ Second Testing } \\
\hline & $\mathrm{d} f$ & MS & $F$ & $\mathrm{p}$ & $d f$ & MS & $\mathrm{F}$ & $\mathrm{p}$ \\
\hline Between Subjects & 7 & & & & 7 & & & \\
\hline Within Subjects & & & & & & & & \\
\hline $\begin{array}{l}\text { Tasks } \\
\text { Residiual }\end{array}$ & $\begin{array}{r}9 \\
63\end{array}$ & $\begin{array}{r}1585.59 \\
48.85\end{array}$ & 32.46 & .01 & $\begin{array}{r}9 \\
63\end{array}$ & $\begin{array}{r}1060.47 \\
37.03\end{array}$ & 28.64 & .01 \\
\hline
\end{tabular}

